\title{
Tetherin does not significantly restrict dendritic cell-mediated HIV-1 transmission and its expression is upregulated by newly synthesized HIV-1 Nef
}

\author{
Christopher M Coleman ${ }^{1}$, Paul Spearman ${ }^{2}$ and Li Wu ${ }^{1 *}$
}

\begin{abstract}
Background: Dendritic cells (DCs) are among the first cells to encounter HIV-1 and play important roles in viral transmission and pathogenesis. Immature DCs allow productive HIV-1 replication and long-term viral dissemination. The pro-inflammatory factor lipopolysaccharide (LPS) induces DC maturation and enhances the efficiency of DCmediated HIV-1 transmission. Type I interferon (IFN) partially inhibits HIV-1 replication and cell-cell transmission in $\mathrm{CD}^{+} \mathrm{T}$ cells and macrophages. Tetherin is a type I IFN-inducible restriction factor that blocks HIV-1 release and modulates $\mathrm{CD}^{+}{ }^{+}$T cell-mediated cell-to-cell transmission of HIV-1. However, the role of type I IFN and tetherin in HIV-1 infection of DCs and DC-mediated viral transmission remains unknown.

Results: We demonstrated that IFN-alpha (IFNa)-induced mature DCs restricted HIV-1 replication and transinfection of $\mathrm{CD}^{+} \mathrm{T}$ cells. Tetherin expression in monocyte-derived immature DCs was undetectable or very low. High levels of tetherin were transiently expressed in LPS- and IFNa-induced mature DCs, while HIV-1 localized into distinct patches in these DCs. Knockdown of induced tetherin in LPS- or IFNa-matured DCs modestly enhanced HIV-1 transmission to CD4 ${ }^{+}$T cells, but had no significant effect on wild-type HIV-1 replication in mature DCs. Intriguingly, we found that HIV-1 replication in immature DCs induced significant tetherin expression in a Nefdependent manner.
\end{abstract}

Conclusions: The restriction of HIV-1 replication and transmission in IFN $\alpha$-induced mature DCs indicates a potent anti-HIV-1 response; however, high levels of tetherin induced in mature DCs cannot significantly restrict wild-type HIV-1 release and DC-mediated HIV-1 transmission. Nef-dependent tetherin induction in HIV-1-infected immature DCs suggests an innate immune response of DCs to HIV-1 infection.

\section{Background}

Dendritic cells (DCs) are professional antigen presenting cells that bridge innate and adaptive immunity. DCs play an important role in innate immune recognition and activation during HIV infection [1,2]. HIV-1 hijacks DCs to promote viral infection and dissemination $[2,3]$. Immature dendritic cells (iDCs) in the mucosa are one of the first cells that encounter HIV-1 during initial infection $[4,5]$. Immature DCs allow productive HIV-1 replication and long-term viral dissemination [6-8].

\footnotetext{
* Correspondence: wu.840@osu.edu

${ }^{1}$ Center for Retrovirus Research, Department of Veterinary Biosciences, The

Ohio State University, Columbus, OH 43210, USA

Full list of author information is available at the end of the article
}

Depending on the stimulus, maturation of DCs has differential effects on HIV-1 replication and cell-to-cell transmission to $\mathrm{CD}^{+} \mathrm{T}$ cells [6,9-13]. DC-mediated dissemination of HIV-1 occurs through the dissociable processes of trans- and cis-infection, depending on whether productive viral infection is initiated in DCs [6]. Productive HIV-1 infection of DCs can induce DC maturation and trigger antiviral innate immunity through type I IFN responses [14].

The major DC subtypes include myeloid DCs and plasmacytoid DCs (pDC) [2,3]. pDCs produce type I IFN upon sensing HIV-1 RNA and envelope protein through Toll-like receptor 7 and other intracellular sensors $[15,16]$. Type I IFNs are antiviral cytokines

\section{C) Biomed Central}


produced as part of the innate immune response to an infection to limit virus dissemination and regulate adaptive immune responses to clear the virus and protect against re-infection [17]. As a type I IFN, IFN $\alpha$ can inhibit HIV-1 replication in $\mathrm{CD}_{4}{ }^{+} \mathrm{T}$ cells and macrophages in vitro $[18,19]$. A recent study indicated that IFN $\alpha$ partially inhibits the cell-to-cell transmission of HIV-1 between $\mathrm{CD}^{+}{ }^{+} \mathrm{T}$ cells [20]. However, it is unknown whether IFN $\alpha$ can block HIV-1 replication in DCs or DC-mediated cell-to-cell transmission of HIV-1.

Type I IFNs can induce the expression of HIV-1 restriction factors [21], in particular, APOBEC3 family proteins [22-24], Trim5 $\alpha$ [25] and tetherin (BST-2 or CD317) [26,27]. Tetherin is a host transmembrane protein $[26,27]$ and is expressed by a wide-range of human and animal cells $[28,29]$. Mouse and human pDCs $[30,31]$ and human monocyte-derived DCs (MDDCs) [29] express endogenous tetherin, though its function is not fully understood. Tetherin has been suggested as a component of the innate immune responses [32]. It has been shown that human pDCs express an orphan receptor called immunoglobulin-like transcript 7 (ILT7), which binds to tetherin and down-regulates the IFN responses of pDCs [31]. This study suggested that type I IFN produced by $\mathrm{pDCs}$ during viral infection may stimulate neighboring cells to express tetherin, which interacts with ILT7 on pDCs to down-modulate IFN and cytokine responses.

Tetherin restricts release of various enveloped viruses, including a number of retroviruses and several viral proteins function as antagonists of tetherin (reviewed in [32-36]). Tetherin acts as an HIV-1 restriction factor by directly tethering HIV-1 virions to the surface of an HIV-producing cell $[27,37]$, but its effect on incoming HIV-1 virions during cell-to-cell transmission has not been documented. The HIV-1 protein Vpu antagonizes tetherin by causing the degradation [38-41] and the sequestration of tetherin into a perinuclear compartment away from the site of virus assembly [42]. Moreover, Nef and envelope proteins from some simian immunodeficiency viruses (SIV) [43-46] and HIV-2 envelope proteins [42,47] function as antagonists of tetherin in a species-specific manner.

It is unknown whether tetherin plays a role in DCmediated HIV-1 infection and transmission. Recent studies suggest different roles of tetherin in the cell-to-cell transmission of HIV-1 mediated by $\mathrm{CD}^{+}{ }^{+} \mathrm{T}$ cells [48-50]. Casartelli et al. reported that tetherin impairs cell-to-cell transmission of HIV-1 in several cell lines and primary $\mathrm{CD}_{4}^{+} \mathrm{T}$ cells, and transmission of $\mathrm{Vpu}-$ defective HIV-1 to target $\mathrm{CD}^{+}{ }^{+} \mathrm{T}$ cells is less efficient than that of wild-type (WT) HIV-1 [49]. By contrast, Jolly et al. suggested that tetherin can enhance HIV-1 cell-to-cell transmission, and Vpu-defective HIV-1 is disseminated more efficiently compared with WT HIV-1 in $\mathrm{CD}^{+}{ }^{+}$Jurkat $\mathrm{T}$ cells [48]. Using tetherin-inducible Sup-T1 cells, Kuhl et al. recently reported that tetherin expressed on target cells promotes HIV-1 cell-to-cell transfer, while tetherin expressed on donor cells inhibits viral transmission [50]. The discrepancy between these studies may be due to cell-type-dependent variation in tetherin expression levels $[49,50]$, which remains to be confirmed using other primary HIV-1 target cells, such as DCs or macrophages.

In this study, we investigated the role of IFN $\alpha$ and tetherin in MDDC-mediated HIV-1 infection and transmission. We demonstrated that IFN $\alpha$ treatment of DCs restricted DC-mediated $\mathrm{HIV}-1$ infection and transmission to $\mathrm{CD}^{+} \mathrm{T}$ cells. We observed that tetherin expression was transiently upregulated in LPS- or IFN $\alpha$ matured DCs and knockdown of induced tetherin modestly enhanced mature DC-mediated HIV-1 transmission, but had no significant effect on WT HIV-1 replication in mature DCs. Intriguingly, we found that tetherin was induced by HIV-1 infection of iDCs in a Nef-dependent manner, suggesting that tetherin upregulation is an innate immune response of DCs to HIV-1 infection.

\section{Results}

IFN $\alpha$ induces DC maturation but does not alter the expression level of HIV-1 receptors

To examine the role of type I IFN in DC-mediated HIV1 infection and transmission, human monocyte-derived iDCs were activated with IFN $\alpha$ to generate mature DCs $(\mathrm{mDC}-\mathrm{IFN \alpha})$ and LPS-induced mature DCs (mDC-LPS) were used as positive controls. DCs were separately stained for surface CD86 as a marker of maturation $[6,11,14,51]$, for the HIV-1 receptors CD4 and CCR5, and for the HIV-1 attachment factor DC-SIGN (DCspecific intercellular adhesion molecule-3 grabbing nonintegrin). Maturation of DCs with either LPS or IFNa caused significant upregulation of CD86 expression on the cell surface by 6- to 7-fold (Figure 1), indicating that both mature DC types developed a mature DC phenotype. Compared with iDCs, mDC-IFN $\alpha$ did not show any significant differences in the expression of CD4, CCR5 or DC-SIGN, while mDC-LPS showed decreased levels of both CD4 and DC-SIGN (Figure 1). Surface CCR5 was equally expressed at low levels on all DC types (Figure 1). Thus, IFN $\alpha$-induced maturation of DCs does not significantly affect the expression of HIV1 receptors.

\section{IFN $\alpha$-induced mature DCs do not mediate efficient HIV-1 transmission to $\mathrm{CD}^{+} \mathrm{T}$ cells}

To assess the effect of IFNa on DC-mediated transmission of HIV-1 to CD4 ${ }^{+} \mathrm{T}$ cells, HIV-1-pulsed mDC- 


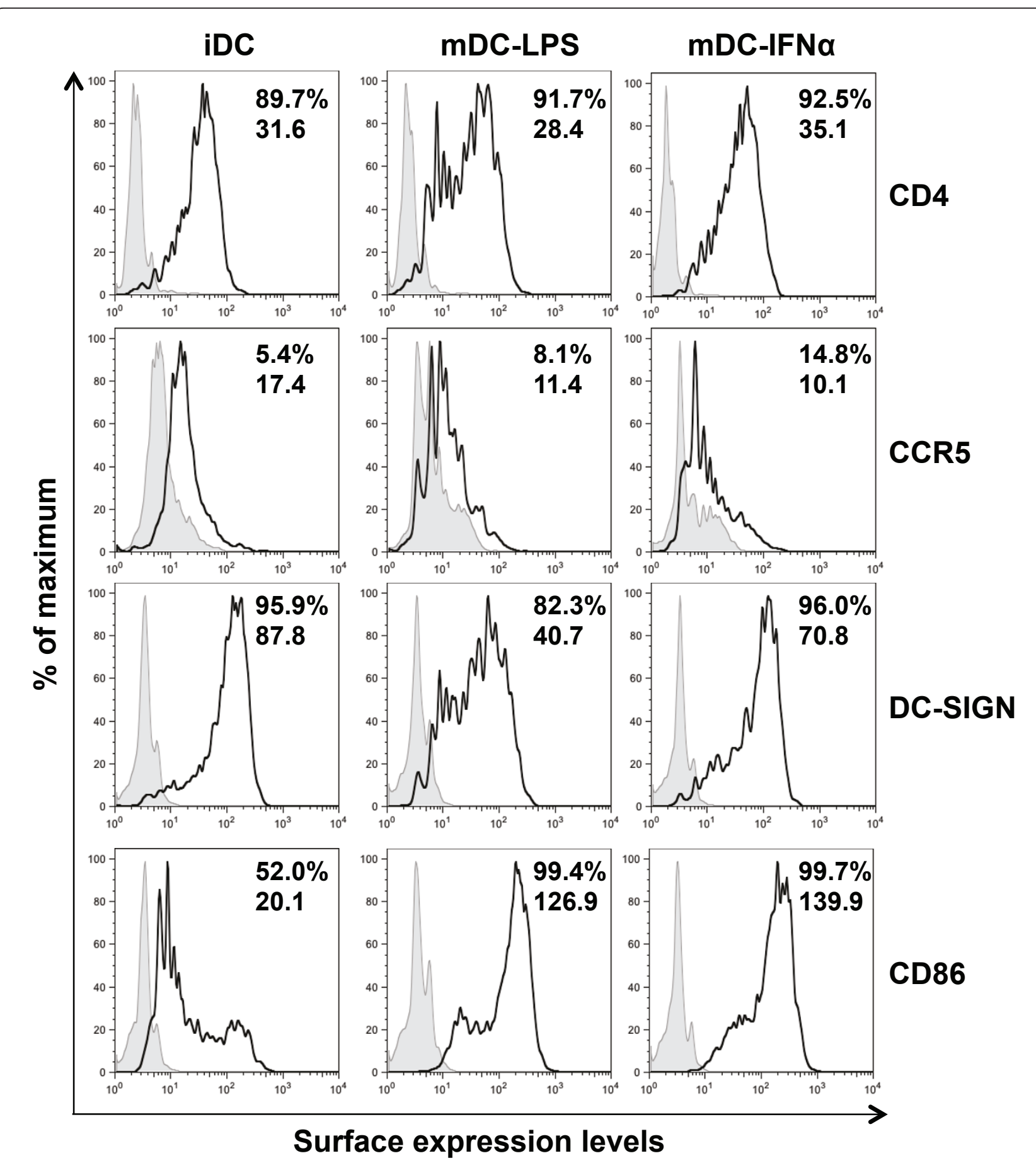

Figure 1 IFN $\alpha$ induces DC maturation but does not alter the expression of HIV-1 receptors. iDC, mDC-LPS and mDC-IFN $\alpha$ were stained for cell surface expression of CD4, CCR5, DC-SIGN and CD86. On each histogram, the filled peaks are the controls of isotype or secondary antibody alone and the black peaks represent the staining of specific markers. Top and bottom numbers shown in plots are \% positive and the geometric mean values of fluorescence intensity, respectively. Results shown are from DCs from a single donor representative of two independent experiments on DCs from different donors. 
IFN $\alpha$ were co-cultured with Hut/CCR 5 cells in viral transmission assays. Single-cycle, R5-tropic luciferase reporter $\mathrm{HIV}-1$ was used and viral transmission was determined by measuring luciferase activity in cell lysates of co-cultures [52]. HIV-1-pulsed DCs alone were used as a control for background replication. $\mathrm{mDC}$-LPS showed a 16 -fold increase in viral transmission compared with iDC-mediated moderate transmission of HIV-1 to CD4 ${ }^{+} \mathrm{T}$ cells (Figure 2A). By contrast, mDC-IFNa failed to enhance single-cycle HIV-1 transmission to $\mathrm{CD}^{+} \mathrm{T}$ cells (Figure $2 \mathrm{~A}$ ).

It has been established that there are two distinct phases in DC-mediated HIV-1 transfer to CD4 $4^{+} \mathrm{T}$ cells [8]. In the first phase (within $24 \mathrm{hr}$ after infection), incoming HIV-1 is transferred, whereas in the second phase (24-72 hr after infection), newly synthesized HIV1 can be transmitted [8]. To examine the two-phase HIV-1 transfer, DC-mediated transmission of replication-competent R5-tropic HIV-1 NL(AD8) was assessed by 24 release in supernatants from the co-cultures of HIV-1-pulsed DCs and Hut/CCR5 cells 2 days later. Compared with iDC-mediated HIV-1 transmission, mDC-LPS transmitted HIV-1 to $\mathrm{CD}^{+}{ }^{+} \mathrm{T}$ cells 5 -fold more efficiently, while mDC-IFN $\alpha$ transmitted HIV-1 only 2-fold more efficiently (Figure 2B). Together, these data indicate that $\mathrm{mDC}$-IFN $\alpha$ do not mediate efficient HIV-1 transmission to $\mathrm{CD} 4^{+} \mathrm{T}$ cells.

\section{Productive HIV-1 replication is restricted in IFN $\alpha$-induced mature DCs}

To understand the mechanism by which IFN $\alpha$ treatment restricts DC-mediated HIV-1 transmission, the kinetics of HIV-1 uptake, degradation and replication in $\mathrm{mDC}$-IFN $\alpha$ were assessed. The reverse transcriptase inhibitor azidothymidine (AZT) was used to confirm productive HIV-1 replication in DCs. HIV-1 enters DCs mainly through endocytosis, but productive HIV-1 infection of DCs is dependent upon fusion-mediated viral entry [6,53], therefore, cell-associated p24 can be indicative of either HIV-1 entry pathway in DCs and supernatant p24 represents productive viral replication and/or viral release.

After $2 \mathrm{~h}$ incubation of DCs with HIV-1 NL(AD8), cells were washed extensively, aliquoted and cultured for up to 7 days. The amount of HIV-1 uptake by DCs was quantified by measuring the cell-associated p24 at $2 \mathrm{~h}$ post-infection. Compared with iDCs, mDC-LPS and mDC-IFNa captured 2-fold more HIV-1 (Figure 2C). Over the time course, iDCs showed increases of both cell-associated p24 (Figure 2C) and released virus (Figure 2D), which were efficiently blocked by AZT, consistent with productive $\mathrm{HIV}-1$ replication. The HIV-1 captured by mDC-LPS were degraded (Figure $2 \mathrm{C}$ ), or otherwise released into the media over time in a largely replication independent manner (Figure 2D). HIV-1 in mDC-IFN $\alpha$ was rapidly degraded, as the cell-associated p24 reached very low levels at 3 days post-infection (dpi) (Figure 2C). Low levels of HIV-1 release from mDC-IFN $\alpha$ was observed at 5 and $7 \mathrm{dpi}$, which was significantly reduced in the presence of AZT (Figure 2D), indicating delayed viral replication in $\mathrm{mDC}$-IFN $\alpha$. These data suggest that IFN $\alpha$ maturation of DCs blocks HIV-1 replication.

\section{Pro-inflammatory stimuli upregulate tetherin expression in DCs}

The above results indicated that HIV-1 replication and release were restricted in IFN $\alpha$ and LPS-induced mature DCs relative to iDCs, which might be attributed to the induction of $\mathrm{HIV}-1$ restriction factors in mature DCs, such as tetherin. We have reported that pro-inflammatory stimuli (such as LPS) induce DC maturation and modulate the efficiency of DC-mediated HIV-1 transmission [6]. To examine whether pro-inflammatory stimuli upregulate tetherin expression in DCs, DCs from different donors were treated with IFN $\alpha$ and LPS and analyzed for tetherin expression on the surface and in whole cell lysates by flow cytometry and immunoblotting, respectively. Cell surface tetherin in iDCs was low or undetectable (Figure 3A, donor 1 and 2, respectively), which correlated well with the levels of tetherin detected in whole cell lysates (Figure 3B). By contrast, high levels of surface tetherin were detected in $\mathrm{mDC}$-LPS (Figure 3A), which correlated well with high levels of tetherin observed in whole cell lysates (Figure 3B). Although the surface tetherin was low or undetectable in $\mathrm{mDC}$-IFN $\alpha$, indicating donor variation of tetherin expression in DCs (Figure 3A), high levels of tetherin were detected in whole cell lysates (Figure $3 \mathrm{~B}$ ), suggesting that the tetherin localization in $\mathrm{mDC}$-IFNa is mainly intracellular.

To examine whether other pro-inflammatory factors could induce tetherin expression, iDCs were treated with tumor necrosis factor alpha (TNF- $\alpha$ ), which has been shown to potently induce DC maturation in our previous study [6]. TNF- $\alpha$ treatment of MDDCs modestly upregulated tetherin expression (Figure $3 \mathrm{C}$ ). The specificity of the tetherin antibody was confirmed using tetherin-negative 293T cells and tetherin-positive HeLa cells (Figure 3D). Thus, treatment of DCs with proinflammatory stimuli causes upregulation of tetherin, but sub-cellular localization of tetherin can be dependent upon the type of stimulus.

\section{HIV-1 co-localizes with tetherin in mature DCs}

Tetherin can show variable sub-cellular localization $[27,28,42,54,55]$ and the localization of tetherin within a cell is critical for its antiviral function [54]. To examine 


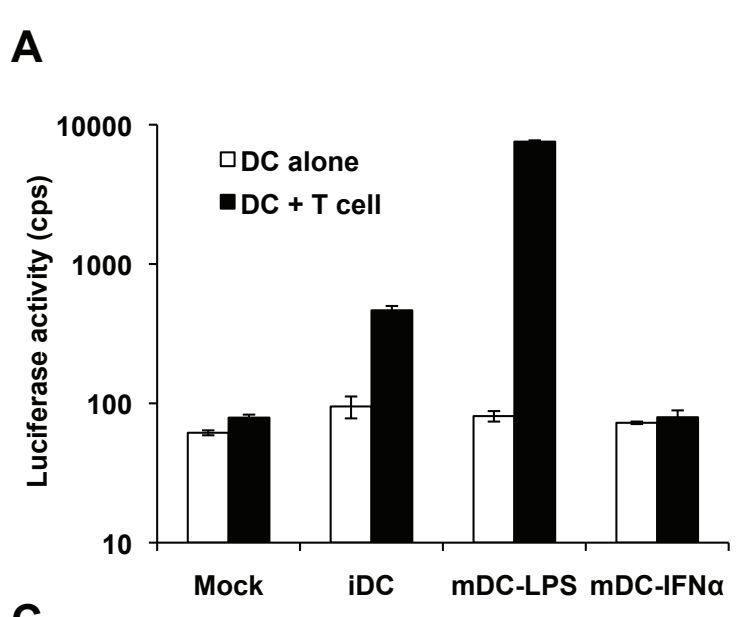

B

C
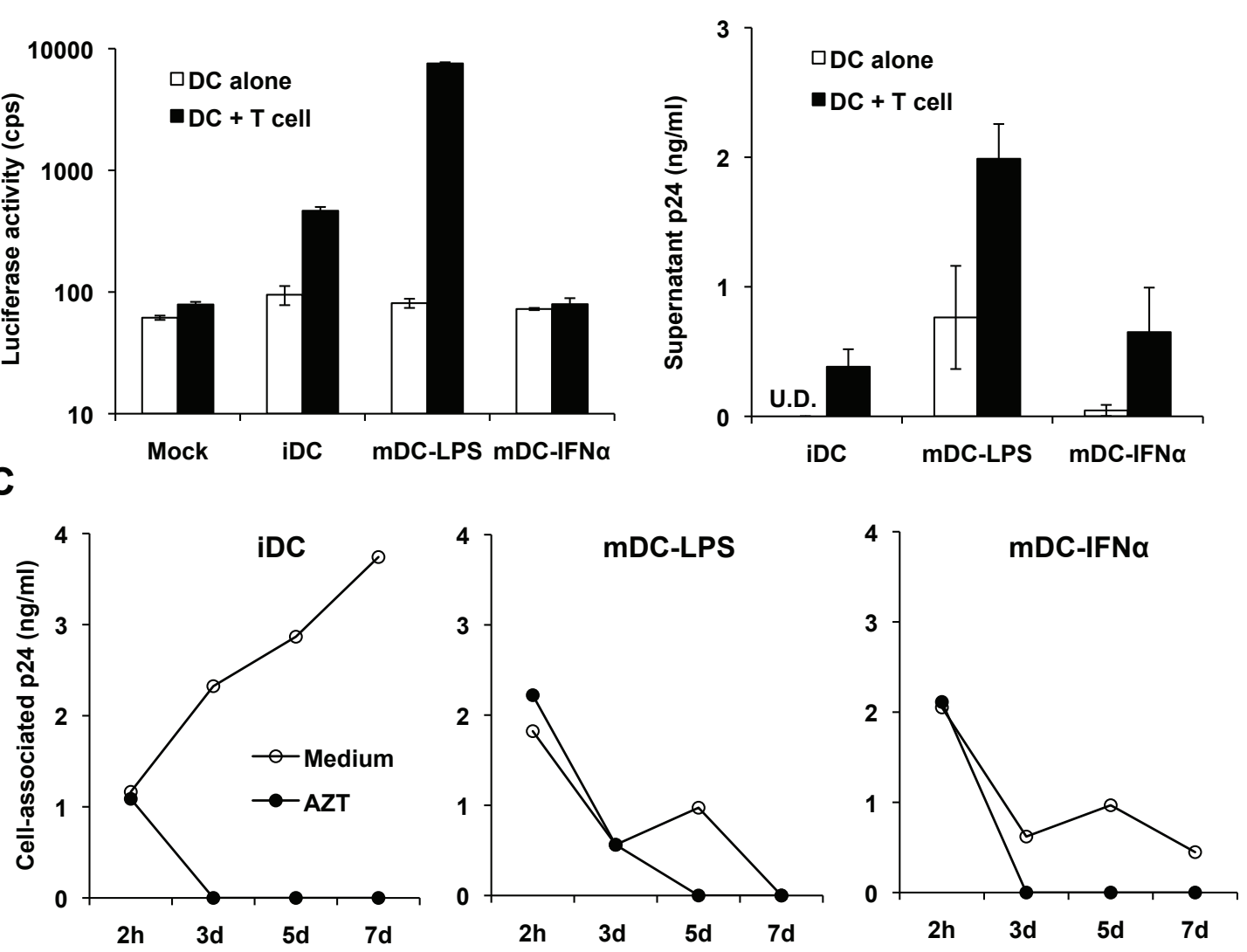

D

Time post-infection
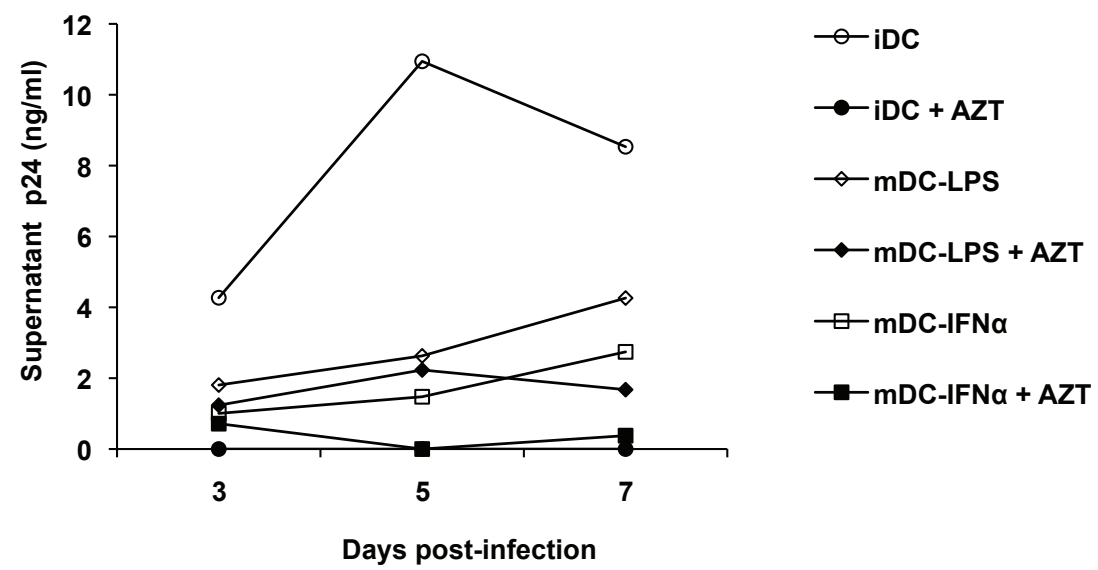

Figure 2 Transmission and replication of HIV-1 is restricted in mDC-IFN $\alpha$. Transmission of HIV-1 by DCs was assessed by incubating DCs with either the single-cycle luciferase reporter HIV-1 or replication-competent HIV-1 NL(AD8) for 2 h, then co-cultured with Hut/CCR5 target cells for 3 or 2 days, respectively; transmission was assessed by whole-cell luciferase assay or release of p24 in supernatants. (A) mDC-IFNa do not enhance transmission of the single-cycle luciferase reporter virus to CD4 ${ }^{+} \mathrm{T}$ cells over iDC transmission levels. cps, counts per second. Mock, mock infected iDCs. Data represent mean \pm SEM of three independent experiments performed on DCs from three different donors. U.D., undetectable (lower than detection limit). (B) mDC-IFNa do not enhance transmission of HIV-1 NL(AD8) to CD4 ${ }^{+}$T cells at 2 dpi (days postinfection) relative to iDC transmission levels. Graph represents mean data \pm SEM from three independent experiments performed with DCs from three different donors. DCs were infected with WT NL(AD8) and p24 production in the cell lysates (C) or supernatants (D) was monitored after 2 h or 3-7 dpi using a p24 ELISA. AZT was used to assess productive HIV-1 infection. Data are from one experiment and representative of at least two independent experiments. 
A $\square$ Control antibody - Anti-tetherin
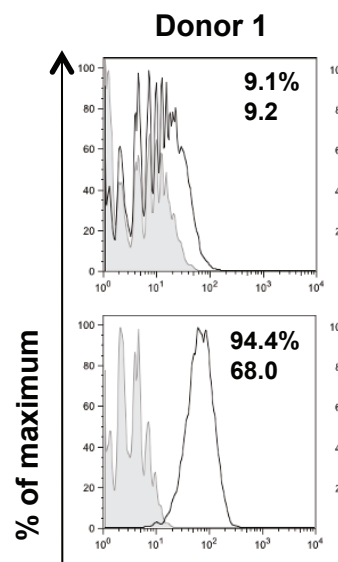

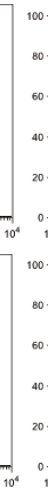

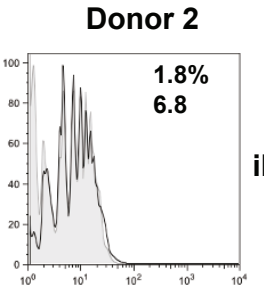

Donor 2

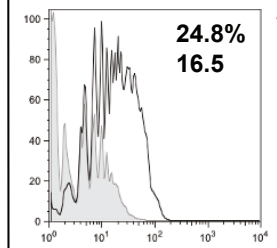

Tetherin surface expression

C

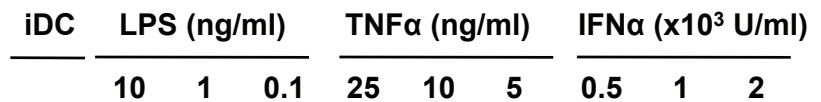

mDC-IFNa
B

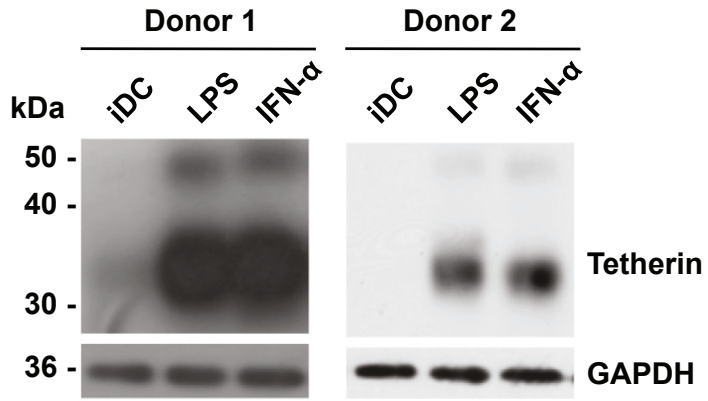

Tetherin

Donor 3

GAPDH

D

Control antibody - Anti-tetherin

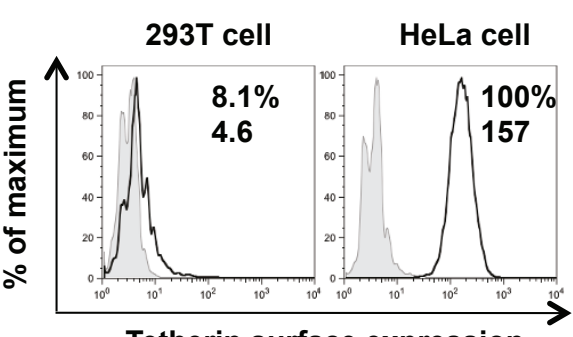

Tetherin surface expression

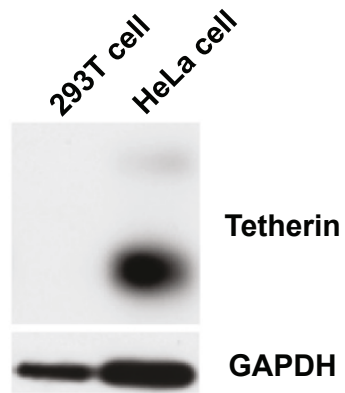

Figure 3 Pro-inflammatory stimuli upregulate tetherin expression in DCs. Tetherin expression on iDCs, mDC-LPS and mDC-IFN $\alpha$ from two different donors was assessed by (A) flow cytometry and (B) immunoblotting. (C) TNF- $\alpha$ treatment of DCs modestly upregulates tetherin expression compared with mDC-LPS and mDC-IFN $\alpha$. Tetherin expression was detected by immunoblotting. (D) HEK293T and HeLa cells were used as negative and positive controls, respectively. Numbers shown in flow cytometry plots are \% positive (top) and the geometric mean values of fluorescence intensity (bottom) for each histogram. 
the localization of HIV-1 with tetherin in mature DCs, confocal microscopy was used after a $2 \mathrm{~h} \mathrm{HIV-1} \mathrm{infec-}$ tion of DCs. GFP-Vpr-tagged replication-competent HIV-1 (HIV-GFP-Vpr) [56] was used to visualize the localization of HIV-1 in mature DCs. Previous studies have shown that in mDC-LPS, HIV-1 strongly concentrates in an intense patch [10] and co-localizes with the tetraspanin CD81 $[12,57,58]$, but not with lysosomal associated membrane protein-1 (LAMP-1) [58]. Therefore, DCs were stained for CD81, LAMP-1, and tetherin to determine the sub-cellular localization of HIV-1.

Consistent with previous reports $[12,57,58]$, HIV-GFPVpr localized into an intense patch with CD81 and did not co-localize with LAMP-1 in mDC-LPS (Figure 4A), which was confirmed by the correlation analysis of colocalization (Figure 4B). Furthermore, the intense patch of HIV-1 observed in mDC-LPS co-localized with tetherin (Figure 4A) and the correlation analysis confirmed the co-localization (Figure 4B). In mDC-IFN $\alpha$, HIV-GFP-Vpr localized into smaller patches near the plasma membrane (Figure 4C) and showed co-localization with CD81 (Figure 4C), with the correlation coefficient being similar to that observed in $\mathrm{mDC}$-LPS (Figure $4 \mathrm{~B}$ and 4D). HIV-Vpr-GFP did not co-localize with LAMP-1 in mDC-IFN $\alpha$ (Figure 4C) and the correlation coefficient was very low (Figure 4D). The punctate patches of HIV-1 in mDC-IFN $\alpha$ appeared to localize with tetherin (Figure 4C and 4D). These data indicate that in $\mathrm{mDC}$-IFN $\alpha$ and $\mathrm{mDC}$-LPS, HIV-1 localizes into distinct patches that co-localize with CD81 and tetherin but not with LAMP-1. These results suggest that LPSand IFN $\alpha$-induced tetherin expression may affect HIV-1 trafficking and transmission in mature DCs.

\section{Tetherin knockdown in mature DCs modestly enhances HIV-1 transmission to $\mathrm{CD}^{+} \mathrm{T}$ cells}

To examine the role of tetherin in mature DC-mediated HIV-1 transmission to CD4 ${ }^{+} \mathrm{T}$ cells, tetherin expression in mature DCs was silenced with specific siRNA. To achieve efficient knockdown, iDCs were nucleofected with tetherin-specific or control siRNA and matured with LPS or IFN $\alpha$. Analyses of tetherin expression at 2 days post nucleofection confirmed efficient knockdown of surface tetherin in $\mathrm{mDC}$-LPS (Figure 5A) and total tetherin in $\mathrm{mDC}$-IFNa (Figure $5 \mathrm{C}$ ). To assess DCmediated HIV-1 transmission, tetherin-silenced DCs were pulsed with the single-cycle luciferase reporter HIV-1 and co-cultured with the target Hut/CCR5 cells. Tetherin-silenced $\mathrm{mDC}$-LPS and $\mathrm{mDC}$-IFN $\alpha$ showed a modest $30-50 \%$ increase over the scramble siRNA controls in transmission of HIV-1 to Hut/CCR5 cells (Figure $5 \mathrm{~B}$ and $5 \mathrm{D})$, though the differences were statistically significant $(P<0.01)$. These data suggest that high levels of tetherin induced in mature DCs can modestly impair DC-mediated transmission of HIV-1 to CD $4^{+} \mathrm{T}$ cells.

\section{Induced tetherin in mature DCs has different effects on WT and Vpu-deleted HIV-1 replication and DC-mediated HIV-1 transmission to $\mathrm{CD}^{+}{ }^{+} \mathrm{T}$ cells}

To further examine the role of induced tetherin in replication-competent HIV-1 infection and transmission mediated by DCs, we assessed the effect of tetherin knockdown on the release of WT and Vpu-deleted $(\triangle \mathrm{Vpu}) \mathrm{HIV}-1$ from infected mature DCs and on DCmediated HIV-1 transmission to Hut/CCR5 cells. Efficient tetherin knockdown was achieved in mDC-LPS and $\mathrm{mDC}$-IFN $\alpha$ (Figure 5A,C and data not shown). Tetherin-silenced mature DCs were infected with WT $\mathrm{NL}(\mathrm{AD} 8)$ or $\Delta \mathrm{Vpu} \mathrm{NL}(\mathrm{AD} 8)$ and HIV-1 p24 in the supernatants was assessed at $5 \mathrm{dpi}$, which was generally the peak of HIV-1 replication in iDCs (Figure 2D). Tetherin knockdown in $\mathrm{mDC}$-LPS had no significant effect on the release of WT HIV-1, while the release of $\Delta \mathrm{Vpu} H I V-1$ was inhibited 2-fold upon tetherin knockdown (Figure 6A). By contrast, the release of WT and $\triangle \mathrm{Vpu}$ HIV-1 from mDC-IFNa was enhanced by $38 \%$ and 2-fold upon tetherin knockdown, respectively (Figure 6B). HIV-1 infections of tetherin-silenced mature DCs were performed three times with different donors' cells and there was no statistically significant difference in WT HIV-1 release. Thus, induced tetherin expression in mature DCs does not play a major role in restriction of WT HIV-1 replication.

We next assessed the effect of tetherin knockdown on WT and $\triangle \mathrm{Vpu}$ HIV-1 transmission from mature DCs to $\mathrm{CD}^{+}{ }^{+} \mathrm{T}$ cells. Upon tetherin knockdown in mDC-LPS, transmission of WT and $\triangle \mathrm{Vpu}$ HIV-1 was inhibited by $25 \%$ and 2 -fold, respectively (Figure 6C). By contrast, upon tetherin knockdown in $\mathrm{mDC}$-IFN $\alpha$, transmission of WT HIV-1 was enhanced 2-fold, while transmission of $\Delta \mathrm{Vpu} H \mathrm{HV}-1$ was not significantly affected (Figure 6D). As a background control of HIV-1 transmission assays, there were low levels of HIV-1 release from HIV-1-infected DC alone samples (Figure 6C and 6D). Together, these results suggest that induced tetherin in mDC-LPS and mDC-IFN $\alpha$ has different effects on $\triangle \mathrm{Vpu} H I V-1$ replication and transmission, which might be due to the distinct tetherin localization in these cells.

\section{HIV-1 replication in iDCs upregulates tetherin independently of $\mathrm{Vpu}$}

To examine the role of $\mathrm{Vpu}$ and tetherin interactions in HIV-1 infection of DCs, DCs were separately infected with WT NL(AD8) and $\triangle \mathrm{Vpu}$ HIV-1, and viral replication was assessed by $\mathrm{p} 24$ production in the supernatants over a time course. There was no significant defect in 


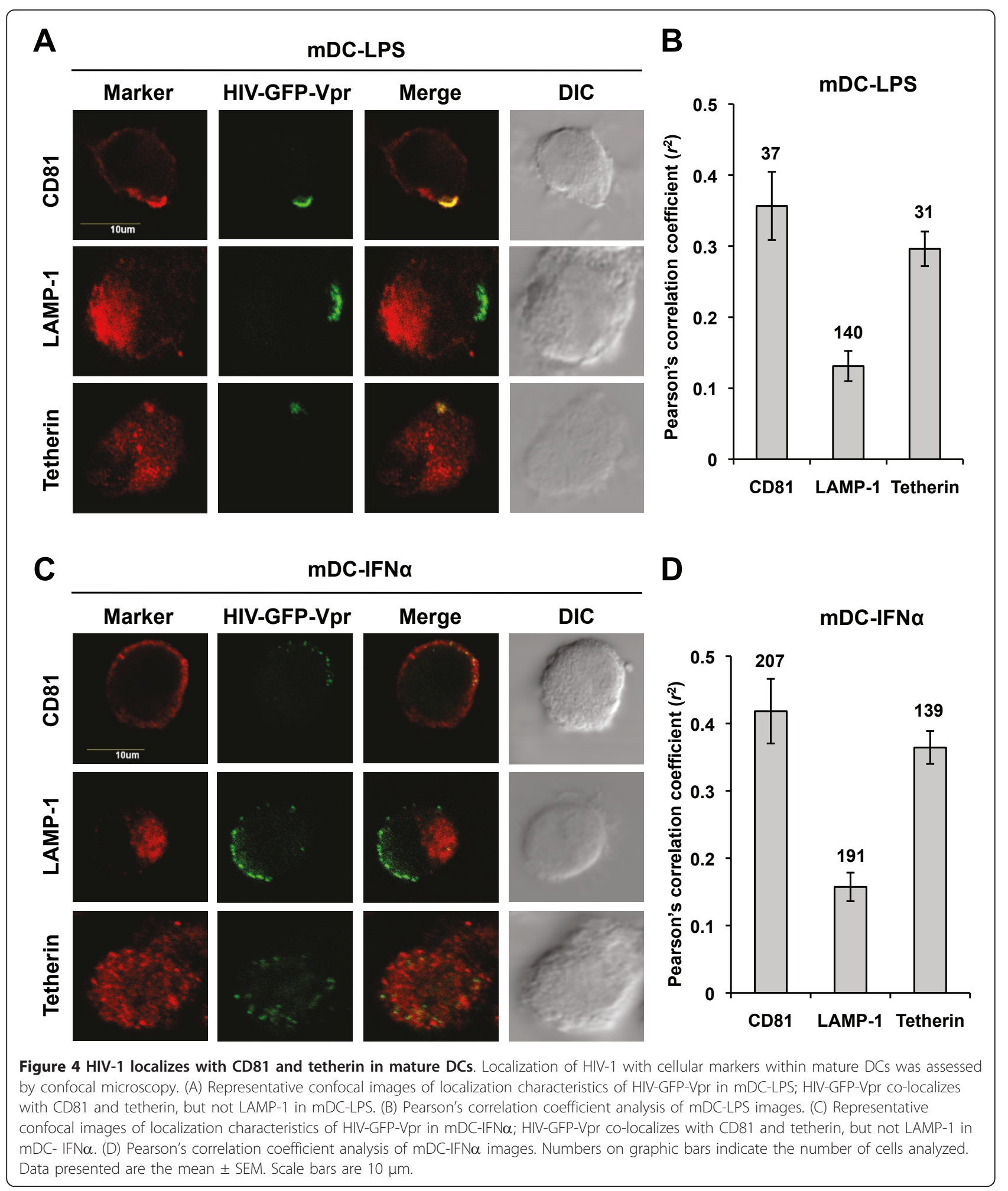

p24 production from infected iDCs and mDC-IFNa when Vpu was absent (Figure 7A). A 40\% decrease of p24 release was observed from $\mathrm{mDC}$-LPS at $7 \mathrm{dpi}$ in the absence of Vpu (Figure 7A), suggesting that Vpu could partially counteract tetherin-mediated restriction of HIV-1 release.

HIV-1 infection of certain cell types can modulate tetherin surface expression $[28,59,60]$. However, no 


\section{A}

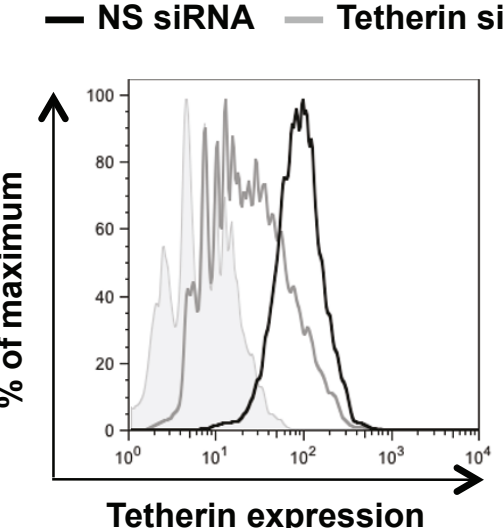

C

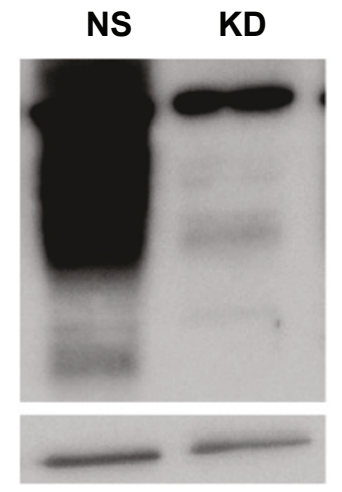

Tetherin

GAPDH
B

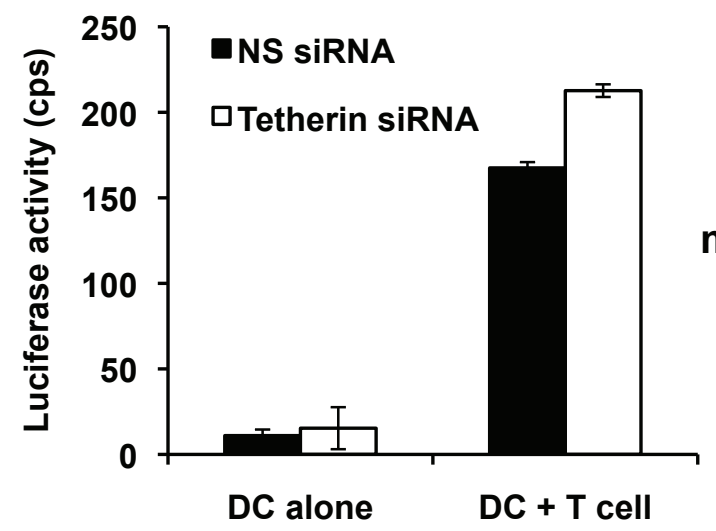

mDC-LPS

D

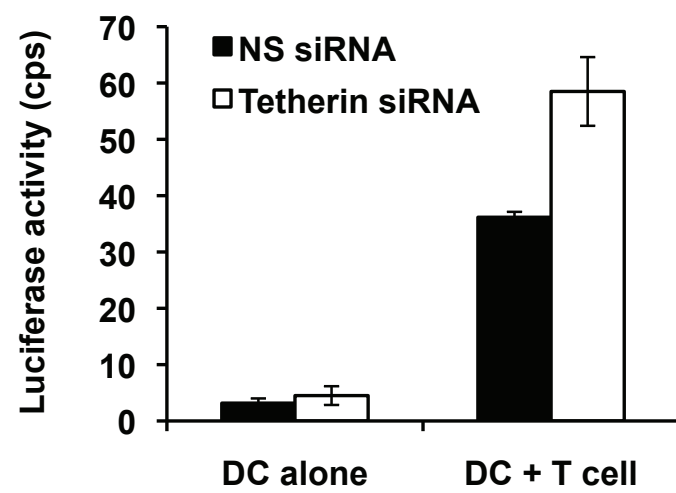

mDC-IFNa

Figure 5 Tetherin knockdown in mature DCs modestly enhances HIV-1 transmission to CD4 ${ }^{+} \mathrm{T}$ cells. Due to the differential localization of tetherin in matured DCs (Figure 3), tetherin knockdown was verified in (A) mDC-LPS by flow cytometry and in (C) mDC-IFNa by

immunoblotting. Each plot is representative of three independent experiments performed. NS, non-silencing scramble siRNA control; KD, knockdown using tetherin siRNA. Tetherin knockdown in (B) mDC-LPS and (D) mDC-IFNa significantly enhanced transmission of single-cycle luciferase HIV-1 to Hut/CCR5 cells. Each graph represents mean results \pm SEM of two independent experiments performed on DCs from different donors.

study has examined the effect of HIV-1 infection on tetherin expression in DCs. To assess whether HIV-1 infection affects the level of tetherin expression in DCs, iDCs, mDC-LPS and mDC-IFNa were separately infected with WT NL(AD8) and $\triangle \mathrm{Vpu}$, and the expression of tetherin and HIV-1 Gag in DCs at $2 \mathrm{~h}$ and 3-7 days post-infection were assessed by immunoblotting. The p24 bands detected in all DC types at $2 \mathrm{~h}$ postinfection were from input HIV-1 associated with DCs (Figure 7B-D), and mDC-LPS efficiently endocytosed HIV-1 (Figure 7C). In iDCs infected with WT and $\Delta$ Vpu HIV-1, there was a clear emergence of Gag p55 and p24, indicative of virus replication, and there was a corresponding induction of tetherin expression at $3 \mathrm{dpi}$ (Figure 7B). Tetherin expression in HIV-1 infected iDCs appeared to diminish over time in a Vpu-independent manner (Figure 7B). These results suggest that HIV-1 infection of iDCs induces significant tetherin expression despite Vpu expression. In mDC-LPS and $\mathrm{mDC}$-IFN $\alpha$, high levels of DC maturation-induced tetherin were detected at $2 \mathrm{~h}$ post-infection, but the levels of tetherin in the mock-infected controls diminished after $3 \mathrm{dpi}$ (Figure 7C and 7D). HIV-1-infected mature DCs showed consistently higher tetherin expression than mock infected controls, which also diminished over time in a Vpu-independent manner (Figure 7C and 7D). Notably, in $\mathrm{mDC}$-IFN $\alpha$, when low levels of HIV-1 productive replication were observed at $7 \mathrm{dpi}$ (Figure 2D and 7D), there was a slight increase in tetherin expression (Figure 7D), suggesting that HIV-1 replication can induce tetherin expression in DCs. Furthermore, we compared cell surface levels of tetherin expression in WT and $\Delta \mathrm{Vpu}$ HIV-1 infected iDCs. Flow cytometry analysis confirmed that WT HIV-1 and $\Delta \mathrm{Vpu}$-infected iDC 
A

mDC-LPS replication

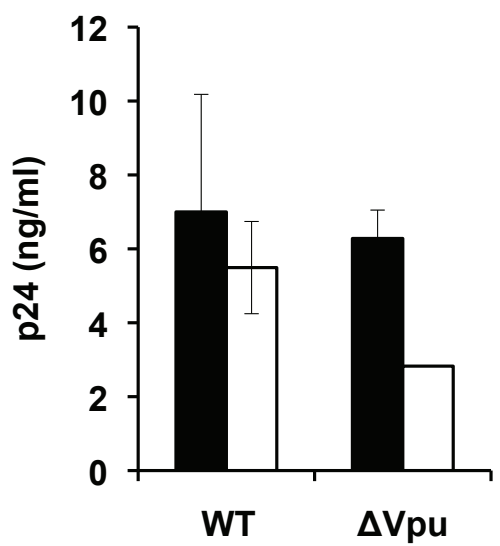

C

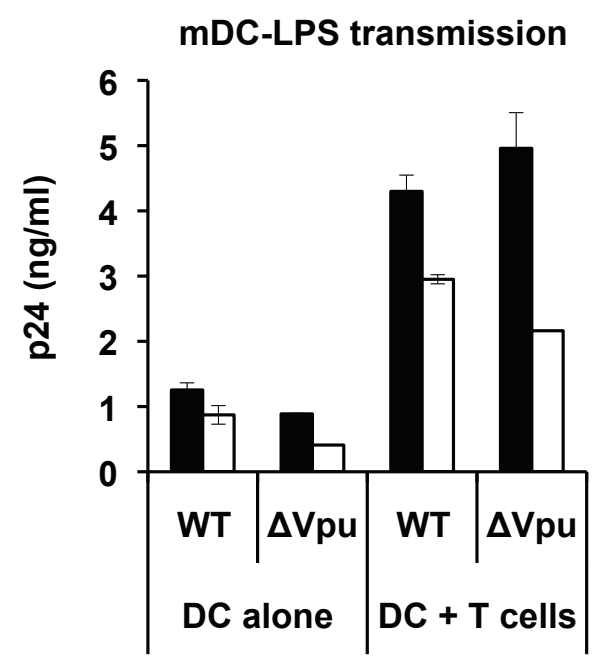

B

mDC-IFNa replication

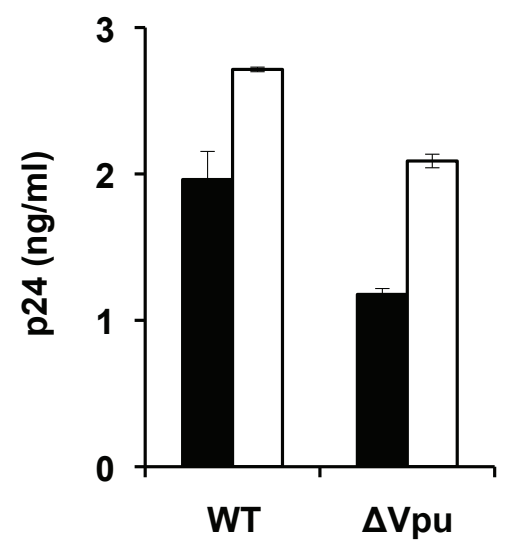

NS siRNA

Tetherin siRNA

D

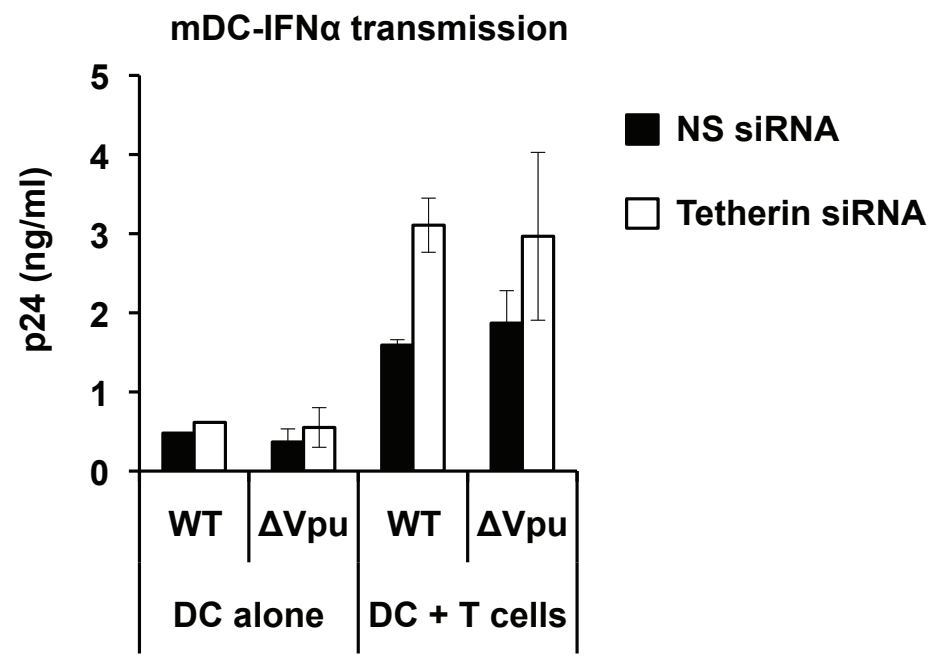

Figure 6 Induced tetherin in mature DCs has different effects on WT and Vpu-deleted HIV-1 replication and DC-mediated HIV-1 transmission to $\mathrm{CD4}^{+} \mathrm{T}$ cells. (A and B) The effect of tetherin on HIV-1 replication in mature DCs was assessed by tetherin knockdown and infection with WT NL(AD8) or NL(AD8) $\triangle V$ pu. Supernatant p24 in mDC-LPS (A) or mDC-IFNa (B) nucleofected with tetherin-specific siRNA or a non-silencing (NS) scramble siRNA control were assessed by p24 ELISA at 5 days post-infection. (C and D) The effect of tetherin on cell-to-cell transmission of WT NL(AD8) or NL(AD8) $\triangle$ Vpu from tetherin-specific or NS siRNA nucleofected mDC-LPS (C) or mDC-IFNa (D) to Hut/CCR5 cells. Supernatants were collected after 2 days of co-culture and p24 concentration was assessed by ELISA. Graphs represent data from one donor representative of at least two experiments performed on DCs from different donors. Data are presented as mean \pm SEM of duplicate samples.

similarly upregulated tetherin surface expression at 3 and 5 dpi compared with mock-infected cells (Figure $7 E)$.

HIV-1 replication in iDCs upregulates tetherin in a Nefdependent manner

A previous study suggested that the upregulation of tetherin surface expression by HIV-1 infection in macrophages appears to be Nef-dependent [59]. To investigate whether tetherin induction by HIV-1 in DCs was dependent on Nef synthesized during viral infection, iDCs were separately infected with WT NL(AD8) and Nefdeleted mutant $(\triangle \mathrm{Nef})$ in the presence or absence of AZT. The expression of tetherin and HIV-1 Gag in DCs was assessed by immunoblotting at $5 \mathrm{dpi}$, which represented the peak of HIV-1 replication in iDCs (Figure 2D). WT HIV-1 infection of iDCs induced tetherin expression at $5 \mathrm{dpi}$, which could be abolished by AZT 


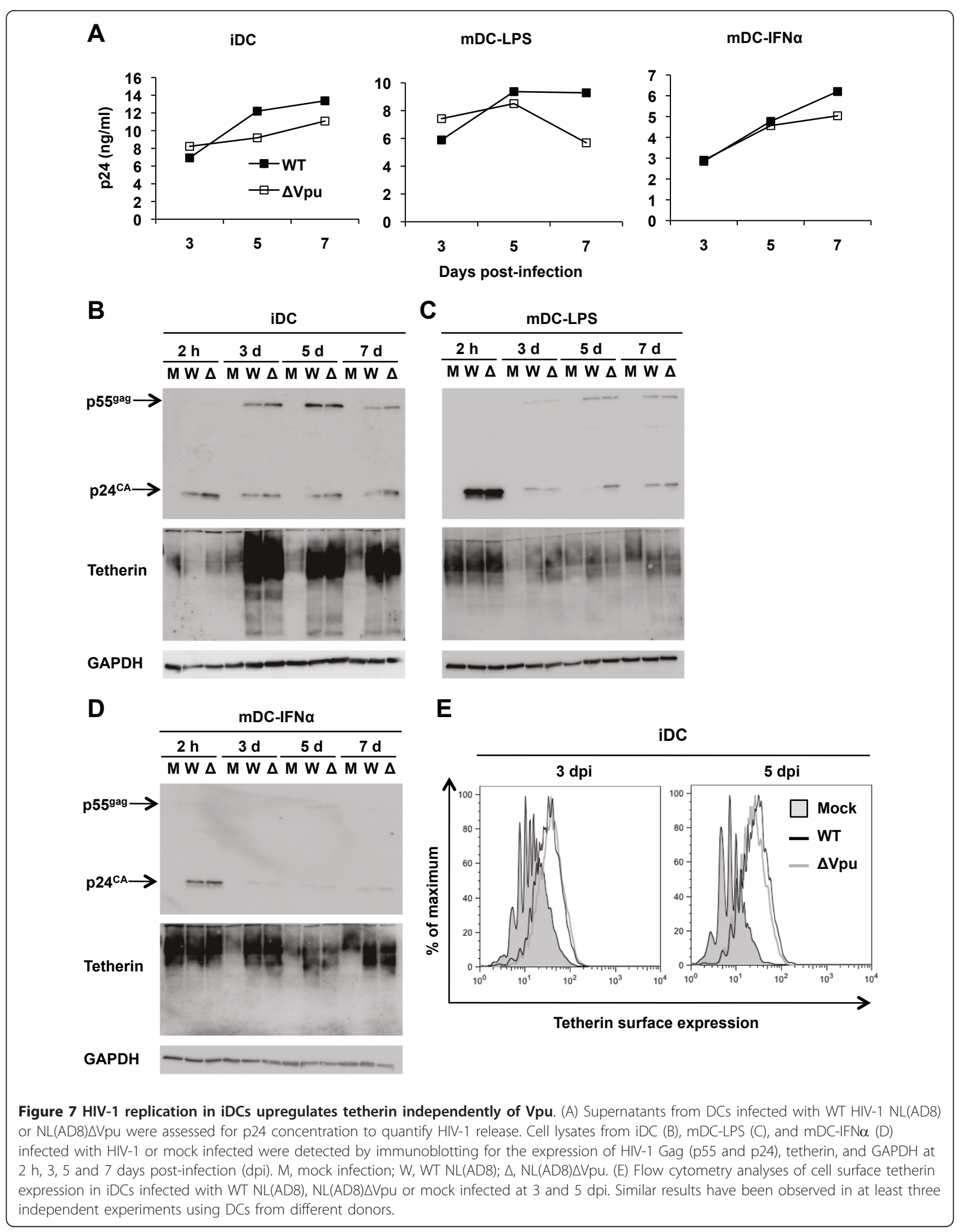


treatment (Figure 8A). The $\triangle \mathrm{Nef}$ HIV-1 mutant failed to induce tetherin, despite similar Gag production relative to WT HIV-1 infection (Figure 8A). Furthermore, flow cytometry analysis of tetherin expression in infected DCs confirmed that WT HIV-1 but not $\Delta$ Nef mutant induced tetherin surface expression (Figure 8B). Thus, HIV-1 replication in iDCs induces transient upregulation of tetherin expression due to the production of Nef.

Nef enhances the expression levels of mRNA encoding IFN-induced protein with tetratricopeptide repeats 1 (IFIT1) in HIV-1-infected iDCs

To explore the underlying mechanisms of Nef-dependent tetherin induction in HIV-1-infected iDCs, we quantified mRNA levels of IFIT-1, an IFN stimulated gene (ISG), in WT HIV-1 NL(AD8) or $\Delta$ Nef-infected iDCs using real-time RT-PCR. Compared with mock infection, WT and $\triangle \mathrm{Nef} H I V-1$ infections in iDCs resulted in a 5-fold increase of IFIT1 mRNA levels at 6 hr post-infection (Figure 9). At 16 and $48 \mathrm{hr}$ post-infection, WT HIV-1 increased IFIT1 mRNA levels in infected iDCs 44- and 40-fold, respectively, relative to mock infection. By contrast, $\triangle$ Nef HIV-1 infection in iDCs increased IFIT1 mRNA levels 13- and 27-fold at 16 and $48 \mathrm{hr}$ post-infection, respectively, compared with mock infection (Figure 9). These data suggest that HIV-

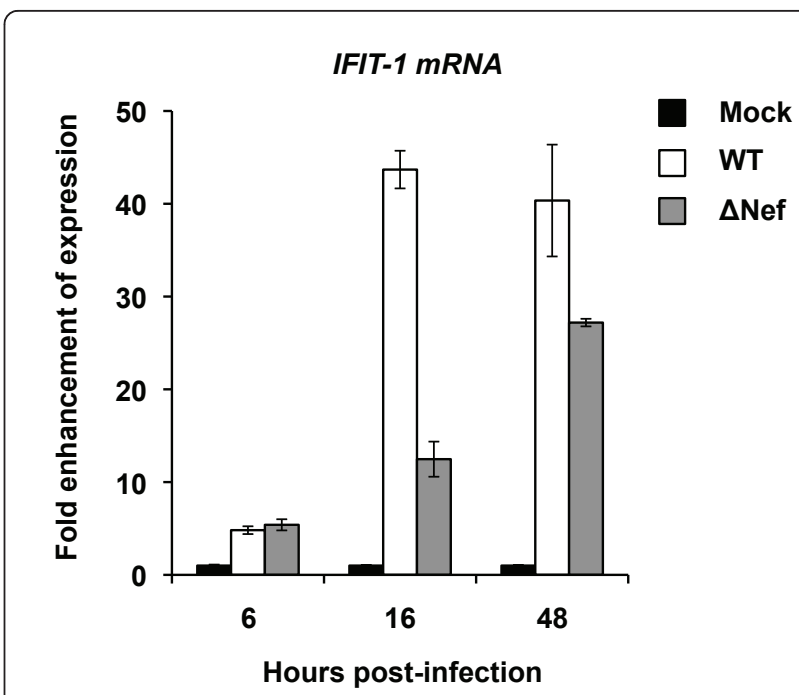

Figure 9 Nef enhances the expression levels of IFIT-1 mRNA in HIV-1-infected iDCs. The levels of IFIT-1 mRNA in iDCs mock infected or infected with WT NL(AD8) or NL(AD8) $\triangle$ Nef were quantified using real-time RT-PCR. The IFIT-1 expression levels were normalized by the relative GAPDH expression levels. The results of mock-infected controls were assigned as 1 and the fold enhancement of IFIT-1 expression in HIV-1 infected iDCs is shown. WT, wild-type NL(AD8); $\triangle$ Nef, NL(AD8) $\Delta$ Nef. One representative experiment out of three is presented.
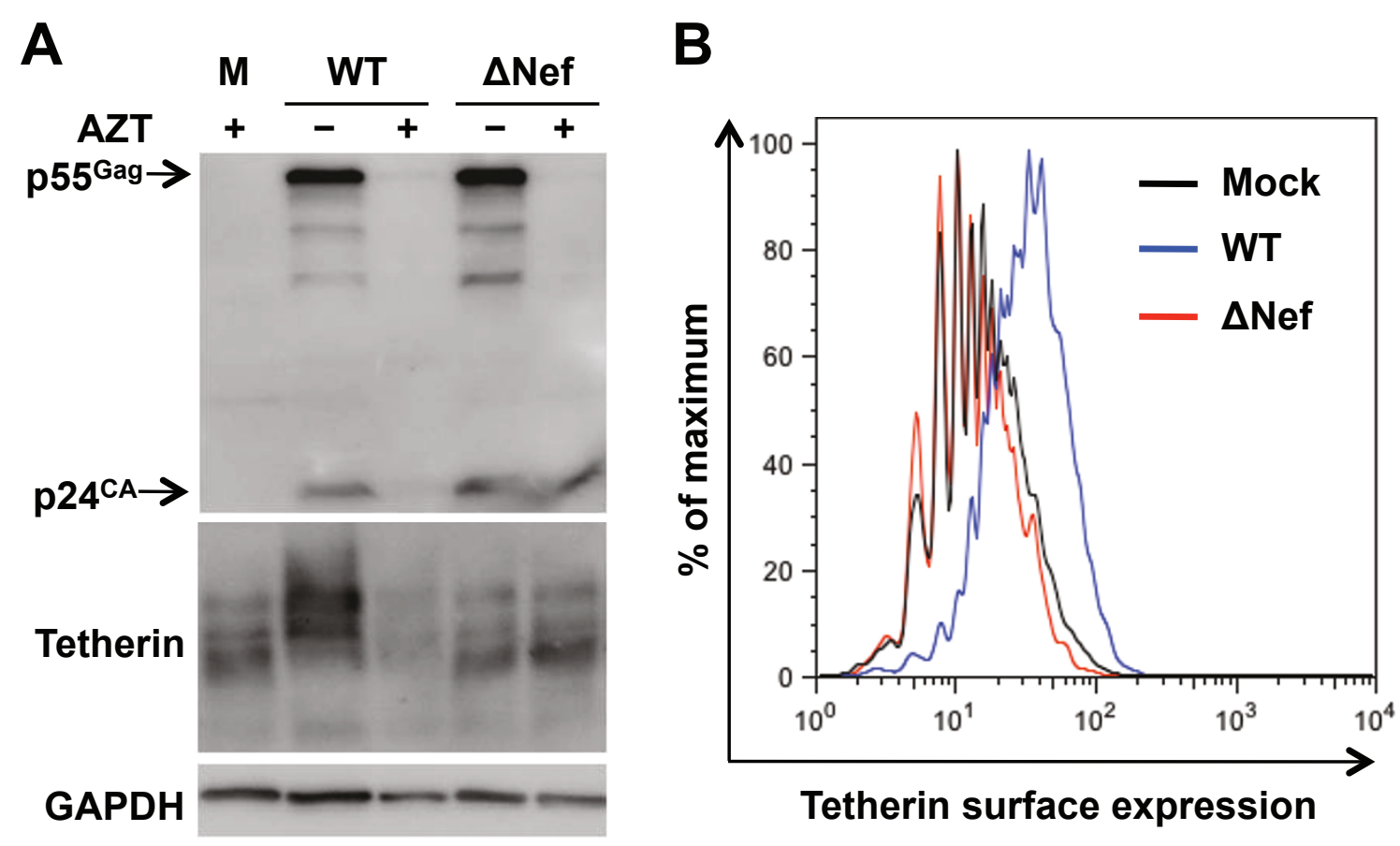

Figure 8 HIV-1 replication in iDCs upregulates tetherin in a Nef-dependent manner. (A) Cell lysates from iDCs infected with WT NL(AD8), $\mathrm{NL}(\mathrm{AD} 8) \triangle \mathrm{Nef}$ with (+) or without (-) AZT or mock infected were evaluated at 5 dpi for the expression of HIV-1 Gag (p55 and p24), tetherin and GAPDH by immunoblotting. (B) Flow cytometry analysis of surface tetherin expression in infected DCs at 5 dpi. M, Mock infection; WT, wild-type $\mathrm{NL}(\mathrm{AD} 8) ; \triangle \mathrm{Nef}, \mathrm{NL}(\mathrm{AD} 8) \triangle \mathrm{Nef}$. One representative experiment out of three is shown. 
1 infection of iDCs induces ISG mRNA expression as an innate immune response, and that Nef plays an important role in this process.

\section{Discussion}

Previous studies indicated that IFN $\alpha$ treatment partially inhibits post-entry HIV-1 replication and cell-tocell transmission in $\mathrm{CD}^{+}{ }^{+} \mathrm{T}$ cells and macrophages [18-20], suggesting type I IFN-mediated anti-HIV responses. Compared with iDCs, mDC-LPS do not support productive HIV-1 replication, but mediate highly efficient cell-to-cell transmission $[2,6,9,11]$. To better understand the innate immune response of DCs to HIV-1 infection, we investigated the effect of IFN $\alpha$ on HIV-1 replication and cell-to-cell transmission using primary human DCs. We found that DCmediated HIV-1 transmission and viral replication were impaired in $\mathrm{mDC}$-IFN $\alpha$. IFN $\alpha$ induced DC maturation but did not affect overall expression levels of HIV-1 receptors and the attachment factor DCSIGN, suggesting that $\mathrm{mDC}$-IFNa can mediate HIV-1 binding and entry. Compared with mDC-LPS, mDCIFN $\alpha$-mediated transmission of HIV-1 to $\mathrm{CD}^{+}{ }^{+} \mathrm{T}$ cells was significantly lower. Our data suggest that IFN $\alpha$ treatment of DCs induces an antiviral response to block HIV-1 replication and cell-to-cell transmission.

IFN $\alpha$ is a major inducer of tetherin expression $[27,61]$, and other pathogenic stimuli have been suggested to stimulate tetherin expression as part of the innate immune response [32]. We thus evaluated any link between tetherin and the inhibition of HIV-1 replication and cell-to-cell transmission in DCs by assessing the levels of tetherin expression in iDCs and mature DCs. We observed that iDCs were extremely low or negative for tetherin expression, while mDC-LPS showed high levels of tetherin expression at the cell membrane. By contrast, mDC-IFN $\alpha$ were negative, or expressed very low levels of surface tetherin despite high levels of whole cell tetherin expression, indicating that IFN $\alpha$-induced tetherin is mainly confined to the intracellular compartment in mDC-IFN $\alpha$. Given the different expression levels and apparent sub-cellular localization patterns of tetherin within DCs, we therefore investigated any link between the high levels of tetherin induced in mature DCs and the HIV-1 replication and cell-to-cell transmission phenotypes observed in these cells.

Tetherin localization and co-localization with HIV-1 is vital to its restriction function, as it must tether the newly formed HIV-1 virions to the cell membrane $[37,49,54,55,61]$. The localization of HIV-1 in mDCIFN $\alpha$ may contribute to restricted HIV-1 transmission to $\mathrm{CD}^{+}{ }^{+} \mathrm{T}$ cells. HIV-1 and CD81 strongly co-localized in mDC-LPS, with clear evidence of concentration of CD81 at the site of HIV-1 binding, as expected
$[12,57,58]$. Co-localization of HIV-1 and CD81 was also observed in $\mathrm{mDC}$-IFN $\alpha$, but there was no evidence of a concentration of CD81 at the sites of HIV-1 binding, suggesting that the localization of HIV-1 is distinct from that observed in mDC-LPS. The lack of co-localization between HIV-1 and LAMP-1 in mDC-LPS and mDCIFNa indicates that HIV-1 did not traffic to the lysosome for degradation in either cell type at $2 \mathrm{~h}$ postinfection. In both $\mathrm{mDC}$-LPS and $\mathrm{mDC}$-IFN $\alpha$, co-localization of tetherin and HIV-GFP-Vpr was observed, which raises questions about whether tetherin affects incoming HIV-1 captured by mature DCs.

We sought to investigate the direct effect of tetherin on the replication and DC-mediated transmission of HIV- 1 by silencing tetherin in $\mathrm{mDC}$-LPS and $\mathrm{mDC}$ IFN $\alpha$. Recent studies of the tetherin function in HIV-1 cell-to-cell spread have focused on viral transmission from infected $\mathrm{CD} 4^{+} \mathrm{T}$ cells to uninfected cells [48-50]. However, in DC-mediated HIV-1 transmission, DC-captured virus is concentrated at, or near, the cell surface and can be transmitted to $\mathrm{CD} 4^{+} \mathrm{T}$ cells without productive replication in DCs $[2,6,9-12,62]$. Furthermore, the major role of tetherin is to prevent the release of fully formed HIV-1 virions from the cell surface $[27,37,55]$, rather than affecting incoming virions. In a single-cycle HIV-1 transmission assay, tetherin knockdown in mDCLPS and mDC-IFN $\alpha$ resulted in a modest increase of viral transmission to $\mathrm{CD} 4^{+} \mathrm{T}$ cells, suggesting that high levels of induced tetherin in mature DCs may partially impair DC-mediated transmission of incoming HIV-1 to $\mathrm{CD} 4^{+} \mathrm{T}$ cells. It is possible that tetherin siRNA may have potential off-target effect, which should be considered in transient tetherin downregulation in primary DCs. Recent studies indicated that tetherin knockdown in $\mathrm{CD} 4^{+} \mathrm{T}$ cells reduces the formation of the virological synapse and HIV-1 cell-to-cell transmission $[48,49]$. Whether tetherin knockdown affects the formation of the virological synapse between $\mathrm{DCs}$ and $\mathrm{CD} 4^{+} \mathrm{T}$ cells remains to be established.

A recent study indicated that tetherin expressed on target Sup-T1 cells can promote HIV-1 cell-cell transmission [50]. In this study, we focused on the role of tetherin in donor DCs and used Hut/CCR5 T cells as targets in DC-mediated HIV-1 transmission assays. Hut/ CCR5 cells express high levels of endogenous tetherin (data not shown), while primary human $\mathrm{CD} 4^{+} \mathrm{T}$ cells express variable levels of tetherin $[49,63]$. Using Hut/ CCR5 cells avoided donor variations of tetherin expression in primary $\mathrm{CD} 4^{+} \mathrm{T}$ cells. However, it remains to be investigated whether tetherin expressed in $\mathrm{CD} 4^{+} \mathrm{T}$ cell targets affects DC-mediated HIV-1 transfer.

Tetherin inhibits HIV-1 release from cells, and its function is antagonized by Vpu [27,37]. We investigated HIV-1 replication and release in mature DCs using 
tetherin knockdown and a Vpu-defective mutant. The effect of tetherin knockdown on HIV-1 release from mature DCs appears to be dependent upon the maturation stimulus used and on the expression of Vpu by the virus. Our data demonstrate that tetherin expression alone is not responsible for restriction of WT HIV-1 replication in mature DCs. Indeed, previous work has identified other mechanisms responsible for post-entry restriction of HIV-1 replication in MDC-LPS [6]. The restriction of HIV-1 replication in $\mathrm{mDC}$-IFN $\alpha$ may be due to multiple restriction factors. For example, APOBEC3G can block HIV-1 infection in DCs, and its expression is upregulated by IFN $\alpha$ and LPS [24,64].

In iDCs, which do not express high levels of endogenous tetherin, there was a significant increase in tetherin expression in response to the infection with WT and $\Delta \mathrm{Vpu}$ HIV-1. This is consistent with earlier studies that endogenous tetherin in macrophages can be upregulated by HIV-1 infection [59]. When $\mathrm{mDC}$-LPS and $\mathrm{mDC}$ IFN $\alpha$ were infected with WT or $\Delta \mathrm{Vpu}$ HIV-1, tetherin expression was maintained longer than that in mockinfected controls, which is presumably due to stabilization of tetherin or replenishment by tetherin induction. The maintenance of tetherin expression within mature DCs does not appear to be affected by Vpu expression.

Upregulation of surface tetherin in macrophages by HIV-1 infection appears to be induced by Nef [59], and HIV-1 replication in a human $\mathrm{CD} 4^{+}$cell line causes tetherin induction after an initial down-modulation of tetherin [28]. Thus, we investigated the role of both HIV-1 replication and Nef protein in the transient induction of tetherin in iDCs. AZT treatment and deletion of Nef blocked the HIV-1-mediated tetherin upregulation in iDCs. These data suggest a role of newly synthesized Nef in the transient upregulation of tetherin in iDCs. HIV-1 Nef can cause induction of pro-inflammatory cytokines from human DCs and macrophages $[65,66]$, so it is possible that these cytokines act in an autocrine manner to induce transient tetherin expression in DCs as part of an innate immune response to HIV-1 infection. Moreover, an increase in cellular content of tetherin may reflect its stabilization or a slow turn-over upon HIV-1 infection and expression of Nef. The mechanisms by which Nef induces tetherin expression in DCs remain to be elucidated.

Of note, a recent study indicated that HIV-1 infection of MDDCs undermines the IFN induction pathway via interferon regulatory factor 1 (IRF1) and blocks type I IFN production, although HIV-1 infection in DCs induces a subset of ISGs [67]. In agreement with this report, we were not able to detect the release of IFN $\alpha$ or IFN $\beta$ in the supernatants from HIV-1-infected iDCs at 1 to 5 dpi despite significant increases of IFIT-1 mRNA expression.
It is unclear as to why HIV-1 has not evolved a mechanism to block Nef-dependent induction of tetherin in DCs in addition to expressing Vpu as an antagonist of tetherin. Given the apparent transient nature of the Nef-induced tetherin expression in DCs, it is possible that as the tetherin level naturally diminishes over time, it does not affect HIV-1 release at time points of significance. HIV-1-induced tetherin expression also has the potential to ensure that HIV-1 remains in close association with the cell. In the case of DCs, this may allow HIV-1 to stay in close association with the cells during trafficking to the lymph node and subsequent transmission to $\mathrm{CD} 4^{+} \mathrm{T}$ cells at late time points, as is suggested to occur in vivo $[2,5]$.

In summary, we have investigated the role of IFNa and tetherin in DC-mediated HIV-1 infection and transmission. Our data suggest that tetherin is not a major restriction factor for WT HIV-1 replication in DCs or DC-mediated cell-to-cell transmission of HIV-1 to CD4 $4^{+}$ $\mathrm{T}$ cells. Interestingly, we found that HIV-1 infection of iDCs induces Nef-dependent tetherin expression, suggesting an intrinsic antiviral mechanism in DCs triggered by productive HIV-1 infection and the pathogenic factor Nef. Further studies of this mechanism in DCs will provide a better understanding of the innate immune response against HIV-1 infection.

\section{Conclusions}

The restriction of HIV-1 replication and transmission in IFNa-induced mature DCs indicates a potent anti-HIV1 response; however, high levels of tetherin induced in mature DCs cannot significantly restrict WT HIV-1 release and DC-mediated HIV-1 transmission. Nefdependent tetherin induction in HIV-1-infected immature DCs suggests an innate immune response of DCs to HIV-1 infection.

\section{Methods}

\section{Plasmids and HIV-1 stocks}

Single-cycle luciferase reporter HIV-1 was generated by co-transfection of HEK293T cells with pLai3 $\Delta$ envLuc2 (a kind gift from Michael Emerman) and an expression plasmid for R5-tropic HIV-1 IRFL envelope protein as described [68]. The infectivity of viral stocks was assessed by limiting dilution in GHOST/R 5 cells as described [69]. R5-tropic, replication-competent HIV-1 strain $\mathrm{NL}(\mathrm{AD} 8)$ and its derivates, $\mathrm{NL}(\mathrm{AD} 8) \Delta \mathrm{Vpu}$, and $\mathrm{NL}(\mathrm{AD} 8) \Delta \mathrm{Nef}$ were generated by transfection of HEK293T cells separately with pNL(AD8) [70] (a kind gift from Eric Freed), pNL(AD8) $\Delta$ Vpu [71] (a kind gift from Klaus Strebel) or pNL(AD8) $\Delta$ Nef [72] (a kind gift from Olivier Schwartz) as described [68]. HIV-GFP-Vpr was generated by co-transfection of HEK293T cells with pNL(AD8) and a Vpr-GFP expression vector pGFP-Vpr 
(a kind gift from David McDonald) as described [56]. Gag p24 concentrations of viral stocks were measured using an enzyme-linked immunosorbent assay (ELISA; The AIDS Vaccine Program, SAIC, Frederick, MD).

\section{Cell culture}

Monocytes were isolated from buffy coats (American Red Cross Blood Service, Columbus, Ohio) by Histopaque and Percoll (Sigma-Aldrich) gradient centrifugation as described [68]. All DCs utilized in this study were in culture for 7 days post-monocyte isolation. iDCs were generated by incubation of the monocytes in the presence of interleukin 4 and granulocytemacrophage colony stimulating factor for 7 days as described [68]. LPS-induced mature DCs (mDC-LPS) were generated by addition of $10 \mathrm{ng} / \mathrm{ml}$ LPS (Escherichia coli strain O55:B5; Sigma-Aldrich) to day 5 iDCs and subsequently cultured for an additional 2 days. IFN- $\alpha$ matured DCs (mDC-IFN- $\alpha$ ) were generated by addition of $2,000 \mathrm{IU} / \mathrm{ml}$ of recombinant IFN- $\alpha-\mathrm{A} / \mathrm{D}$ (Sigma-Aldrich) to day 6 iDCs and subsequently cultured for an additional one day. iDCs were treated with TNF- $\alpha$ (PeproTech) at the indicated concentrations and cultured for $24 \mathrm{hr}$ before immunoblotting analysis of tetherin expression. HEK293T and HeLa cell lines were maintained in DMEM supplemented with $10 \%$ fetal calf serum, L-glutamine and penicillin and streptomycin. Hut/CCR5 cells (kind gift from Vineet KewalRamani) were grown in selective media as previously described [52].

\section{Flow cytometry analysis of surface marker expression}

DCs were stained with phycoerythrin (PE)- or fluorescein isothiocyanate (FITC)-conjugated antibodies to CD4 (clone number S3.5; Invitrogen), DC-specific intercellular adhesion molecule-3-grabbing non-integrin (DC-SIGN, clone number 120507; R\&D Systems) or CD86 (clone number BU63; Invitrogen). Negative controls were antibodies matched for isotype and fluorescent conjugates: mouse $\operatorname{IgG}_{2 \mathrm{a}}$ (PE conjugate; $\mathrm{BD}$ Biosciences), mouse IgG $_{2}$ (FITC conjugate; BD Bios-

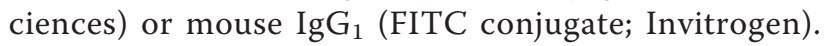
For CCR5 staining, DCs were stained with a purified antibody to CCR5 (clone number 3A9; BD Biosciences), followed by a FITC-conjugated goat anti-mouse secondary antibody (Caltag) as described [53]. Cells were stained for surface tetherin expression using a rabbit serum against tetherin [55] in conjunction with a PE-conjugated goat anti-rabbit $\mathrm{F}_{\mathrm{ab}}$ fragment (BD Biosciences). Stained cells were analyzed on a Guava EasyCyte Mini (Millipore) flow cytometer and data were processed using the FlowJo software (Tree Star). Statistics for percentage positive cells were established by setting up a histogram gate equivalent to $1 \%$ on the relevant negative control cells and utilizing the same gate on stained cells.

\section{Immunoblotting}

Cell lysates were prepared using a Cell Lysis Buffer (Cell Signaling) supplemented with the Protease Inhibitor Cocktail (Sigma-Aldrich) according to the manufacturer's instructions. Following protein quantification using a BCA kit (Pierce), $10 \mu \mathrm{g}$ of each lysate was run on an $8 \%: 13 \%$ SDS-polyacrylamide gel or a $12.5 \%$ Criterion pre-cast gel (Bio-Rad) and transferred to polyvinylidine fluoride membrane (Millipore) using an Electrophoretic Transfer Cell or Semi-Dry Elecrophoretic Transfer Cell (Bio-Rad). Blots were stained with either the anti-tetherin rabbit serum [55], an anti-HIV-1 p24 (clone number 24-2, the NIH AIDS Research and Reference Reagent Program), or an anti-GAPDH (Imgenex), followed by a relevant horseradish peroxidase-conjugated secondary (anti-rabbit or anti-mouse, Promega). Blots were stripped for subsequent probes using Western Blot Stripping Buffer (Thermo Scientific) according to the manufacturer's instructions. Blots were visualized using West Pico chemiluminescent substrates (Thermo Scientific) and a FujiQuick imager (FujiFilm).

\section{Confocal microscopy}

DCs $\left(2 \times 10^{5}\right)$ were pulsed with HIV-Vpr-GFP (20 ng of p24) for $2 \mathrm{~h}$, then washed once with phosphate buffer saline (PBS) and prepared for confocal microscopy [57]. Cells were adhered to a poly-L-lysine coated slide, fixed and permeabilized as described [68]. Cells were labeled using antibodies to CD86 (clone number IT2.2, BD Pharmingen), LAMP-1 (clone number H4A3, BD Pharmingen), and tetherin followed by Alexi-Fluor-568 conjugated anti-mouse or anti-rabbit secondary antibodies (both from Invitrogen). Slides were sealed with Gold anti-fade reagent (Invitrogen) and analyzed on an FV100-Spectral or FV100-Filter confocal microscope (Olympus). Images were processed and co-localization analyses were performed using the FV10-ASW 2.0 Viewer (Olympus).

\section{siRNA knockdown of tetherin in matured DCs}

It has been shown that iDCs are far more receptive to nucleofection than mDC-LPS [6]. To efficiently knockdown tetherin in mature DCs, iDCs were nucleofected with a specific siRNA pool against tetherin and subsequently matured with LPS as described [62]. Amaxa nucleofector and a DC-specific nucleofection kit (Lonza) were used to nucleofect iDCs, according to the manufacturer's instruction. iDCs $\left(2 \times 10^{6}\right)$ were nucleofected with $3 \mu \mathrm{g}$ of a nonspecific siRNA control or a specific siRNA (siGENOME SMARTPOOL) targeting BST-2 (Dharmacon). Nucleofected cells were subsequently 
cultured for 1 day in DC culture media, and then activated with $100 \mathrm{ng} / \mathrm{ml}$ of LPS or $2,000 \mathrm{U} / \mathrm{ml}$ of IFN- $\alpha$ for 1 day to generate mature DCs.

\section{HIV-1 infection and transmission assays}

DCs $\left(2 \times 10^{5}\right)$ at day 7 of culture were challenged with HIV-1 (20 ng of p24) for $2 \mathrm{~h}$ as described [11]. HIV-1 infected DCs were washed once with PBS to remove unbound virions and subsequently cultured for indicated times. Cell lysates and supernatants were collected at indicated times for assessment of p24 concentration by ELISA. Samples were lysed using 1\% Triton X-100 for 1 $\mathrm{h}$ at $37^{\circ} \mathrm{C}$. Where indicated, cells were treated with 1 $\mu \mathrm{M}$ of AZT (NIH AIDS Research and Reference Reagent Program) for the duration of HIV-1 infection and subsequent culture. DC-mediated HIV-1 transmission assays (4 ng of p24 equivalent HIV-1 input) were performed using the Hut/CCR5 cells as target cells as described [6].

\section{RT-PCR quantification of IFIT-1 expression in HIV-1- infected iDCs}

iDCs $\left(2.5 \times 10^{6}\right)$ were mock infected or infected with HIV-1 NLAD8 or NLAD8 $\triangle$ Nef for $2 \mathrm{hr}$, washed with PBS and subsequently cultured for 6, 16 and $48 \mathrm{hr}$. At each indicated time point, cells were harvested and total cellular RNA was extracted using the RNeasy Mini kit (Qiagen) and treated with RNase-free DNase (Ambion). cDNA was synthesized using the SuperScript III firststrand synthesis system (Invitrogen) according to the manufacturer's instruction. The relative levels of cDNA were assessed for spliced glyceraldehyde-3-phosphate dehydrogenase (GAPDH) using specific primers (forward, 5'-GGA AGG TGA AGG TCG GAG TCA ACG G-3'; reverse, 5'-CTG TTG TCA TAC TTC TCA TGG TTC AC-3'), and for IFIT-1 using specific primers (forward, 5'-CAA CCA TGA GTA CAA ATG GTG-3'; reverse, 5'-CTC ACA TTT GCT TGG TTG TC-3'). Real-time PCR was performed with the iQ SYBER Green kit (BioRad) using the CFX96 real-time system as previously described [6].

\section{Statistical analysis}

Data were analyzed using a two-way ANOVA test and Bonferroni post-test. Statistical significance was defined as $P<0.05$.

\section{Acknowledgements}

We thank Drs. M. Emerman, E. Freed, D. McDonald, V. KewalRamani, O. Schwartz, and K. Strebel for the kind gift of reagents. We thank members of the Wu laboratory for helpful discussions and critical reading of the manuscript. Anti-p24 antibody from Michael Malim and AZT were obtained through the NIH AIDS Research and Reference Reagent Program. This work was supported in part by grants to LW (Al068493 and Al078762) from the NIH.

\section{Author details}

${ }^{1}$ Center for Retrovirus Research, Department of Veterinary Biosciences, The Ohio State University, Columbus, OH 43210, USA. ${ }^{2}$ Departments of Pediatrics and Microbiology and Immunology, Emory University, Atlanta, GA 30322, USA.

\section{Authors' contributions}

LW conceived the study, designed the experiments and participated in data analyses. CMC performed all the experiments and participated in the experimental design. PS contributed to some experiment design and data analyses and provided tetherin anti-serum. CMC and LW wrote the manuscript. All authors read and approved the final manuscript.

\section{Competing interests}

The authors declare that they have no competing interests.

Received: 23 January 2011 Accepted: 19 April 2011

Published: 19 April 2011

\section{References}

1. Mogensen TH, Melchjorsen J, Larsen CS, Paludan SR: Innate immune recognition and activation during HIV infection. Retrovirology 2010, 7:54.

2. Wu L, KewalRamani VN: Dendritic-cell interactions with HIV: infection and viral dissemination. Nat Rev Immunol 2006, 6:859-868.

3. Coleman CM, Wu L: HIV interactions with monocytes and dendritic cells: viral latency and reservoirs. Retrovirology 2009, 6:51.

4. Hladik F, Sakchalathorn P, Ballweber L, Lentz G, Fialkow M, Eschenbach D, McElrath MJ: Initial events in establishing vaginal entry and infection by human immunodeficiency virus type-1. Immunity 2007, 26:257-270.

5. Hladik F, McElrath MJ: Setting the stage: host invasion by HIV. Nat ReV Immunol 2008, 8:447-457

6. Dong C, Janas AM, Wang JH, Olson WJ, Wu L: Characterization of human immunodeficiency virus type 1 replication in immature and mature dendritic cells reveals dissociable cis- and trans-infection. J Virol 2007 81:11352-11362.

7. Burleigh L, Lozach PY, Schiffer C, Staropoli I, Pezo V, Porrot F, Canque B, Virelizier $J$, Arenzana-Seisdedos F, Amara A: Infection of dendritic cells (DCs), not DC-SIGN-mediated internalization of human immunodeficiency virus, is required for long-term transfer of virus to $T$ cells. J Virol 2006, 80:2949-2957.

8. Turville SG, Santos JJ, Frank I, Cameron PU, Wilkinson J, Miranda-Saksena M, Dable J, Stossel H, Romani N, Piatak M Jr, et al: Immunodeficiency virus uptake, turnover, and 2-phase transfer in human dendritic cells. Blood 2004, 103:2170-2179.

9. Cavrois M, Neidleman J, Kreisberg JF, Greene WC: In vitro derived dendritic cells trans-infect CD4 T cells primarily with surface-bound HIV-1 virions. PLoS Pathog 2007, 3:e4.

10. McDonald D, Wu L, Bohks SM, KewalRamani VN, Unutmaz D, Hope TJ: Recruitment of HIV and its receptors to dendritic cell-T cell junctions. Science 2003, 300:1295-1297.

11. Wang JH, Janas AM, Olson WJ, Wu L: Functionally distinct transmission of human immunodeficiency virus type 1 mediated by immature and mature dendritic cells. J Virol 2007, 81:8933-8943.

12. Yu HJ, Reuter MA, McDonald D: HIV traffics through a specialized, surfaceaccessible intracellular compartment during trans-infection of $\mathrm{T}$ cells by mature dendritic cells. PLoS Pathog 2008, 4:e1000134.

13. Sanders RW, de Jong EC, Baldwin CE, Schuitemaker JH, Kapsenberg ML, Berkhout B: Differential transmission of human immunodeficiency virus type 1 by distinct subsets of effector dendritic cells. J Virol 2002, 76:7812-7821.

14. Manel N, Hogstad B, Wang Y, Levy DE, Unutmaz D, Littman DR: A cryptic sensor for HIV-1 activates antiviral innate immunity in dendritic cells. Nature 2010, 467:214-217.

15. Beignon AS, McKenna K, Skoberne M, Manches O, DaSilva I, Kavanagh DG, Larsson M, Gorelick RJ, Lifson JD, Bhardwaj N: Endocytosis of HIV-1 activates plasmacytoid dendritic cells via Toll-like receptor-viral RNA interactions. J Clin Invest 2005, 115:3265-3275.

16. Lepelley A, Louis Sp, Sourisseau M, Law HKW, Pothlichet J, Schilte Cm, Chaperot L, Plumas J, Randall RE, Si-Tahar M, et al: Innate Sensing of HIVInfected Cells. PLoS Pathog 2011, 7:e1001284. 
17. Stetson DB, Medzhitov R: Type I interferons in host defense. Immunity 2006, 25:373-381.

18. Poli G, Orenstein JM, Kinter A, Folks TM, Fauci AS: Interferon-alpha but not AZT suppresses HIV expression in chronically infected cell lines. Science 1989, 244:575-577.

19. Goujon C, Malim MH: Characterization of the alpha interferon-induced postentry block to HIV-1 infection in primary human macrophages and T cells. J Virol 2010, 84:9254-9266

20. Vendrame D, Sourisseau M, Perrin V, Schwartz O, Mammano F: Partial inhibition of human immunodeficiency virus replication by type I interferons: impact of cell-to-cell viral transfer. J Virol 2009, 83:10527-10537.

21. Neil S, Bieniasz P: Human immunodeficiency virus, restriction factors, and interferon. J Interferon Cytokine Res 2009, 29:569-580.

22. Peng G, Lei KJ, Jin W, Greenwell-Wild T, Wahl SM: Induction of APOBEC3 family proteins, a defensive maneuver underlying interferon-induced anti-HIV-1 activity. J Exp Med 2006, 203:41-46.

23. Tanaka $Y$, Marusawa $H$, Seno H, Matsumoto $Y$, Ueda $Y$, Kodama $Y$, Endo $Y$, Yamauchi J, Matsumoto T, Takaori-Kondo A, et al: Anti-viral protein APOBEC3G is induced by interferon-alpha stimulation in human hepatocytes. Biochem Biophys Res Commun 2006, 341:314-319.

24. Koning FA, Newman EN, Kim EY, Kunstman KJ, Wolinsky SM, Malim MH: Defining APOBEC3 expression patterns in human tissues and hematopoietic cell subsets. J Virol 2009, 83:9474-9485

25. Asaoka K, Ikeda K, Hishinuma T, Horie-Inoue K, Takeda S, Inoue S: A retrovirus restriction factor TRIM5alpha is transcriptionally regulated by interferons. Biochem Biophys Res Commun 2005, 338:1950-1956.

26. Van Damme N, Goff D, Katsura C, Jorgenson RL, Mitchell R, Johnson MC, Stephens EB, Guatelli J: The interferon-induced protein BST-2 restricts HIV-1 release and is downregulated from the cell surface by the viral Vpu protein. Cell Host Microbe 2008, 3:245-252.

27. Neil SJ, Zang T, Bieniasz PD: Tetherin inhibits retrovirus release and is antagonized by HIV-1 Vpu. Nature 2008, 451:425-430.

28. Sato K, Yamamoto SP, Misawa N, Yoshida T, Miyazawa T, Koyanagi Y: Comparative study on the effect of human BST-2/Tetherin on HIV-1 release in cells of various species. Retrovirology 2009, 6:53,

29. Vidal-Laliena M, Romero X, March S, Requena V, Petriz J, Engel P: Characterization of antibodies submitted to the $B$ cell section of the 8th Human Leukocyte Differentiation Antigens Workshop by flow cytometry and immunohistochemistry. Cell Immunol 2005, 236:6-16.

30. Blasius AL, Giurisato E, Cella M, Schreiber RD, Shaw AS, Colonna M: Bone marrow stromal cell antigen 2 is a specific marker of type I IFNproducing cells in the naive mouse, but a promiscuous cell surface antigen following IFN stimulation. J Immunol 2006, 177:3260-3265.

31. Cao W, Bover L, Cho M, Wen X, Hanabuchi S, Bao M, Rosen DB, Wang YH, Shaw JL, Du Q, et al: Regulation of TLR7/9 responses in plasmacytoid dendritic cells by BST2 and ILT7 receptor interaction. J Exp Med 2009, 206:1603-1614.

32. Evans DT, Serra-Moreno R, Singh RK, Guatelli JC: BST-2/tetherin: a new component of the innate immune response to enveloped viruses. Trends Microbiol 2010, 18:388-396.

33. Tokarev A, Skasko M, Fitzpatrick K, Guatelli J: Antiviral activity of the interferon-induced cellular protein BST-2/tetherin. AIDS Res Hum Retroviruses 2009, 25:1197-1210.

34. Dube M, Bego MG, Paquay C, Cohen EA: Modulation of HIV-1-host interaction: role of the Vpu accessory protein. Retrovirology 2010, 7:114.

35. Kuhl BD, Cheng V, Wainberg MA, Liang C: Tetherin and Its Viral Antagonists. J Neuroimmune Pharmacol 2011, Epub ahead of print.

36. Douglas JL, Gustin JK, Viswanathan K, Mansouri M, Moses AV, Fruh K: The great escape: viral strategies to counter BST-2/tetherin. PLoS Pathog 2010, 6:e1000913.

37. Perez-Caballero D, Zang T, Ebrahimi A, McNatt MW, Gregory DA, Johnson MC, Bieniasz PD: Tetherin inhibits HIV-1 release by directly tethering virions to cells. Cell 2009, 139:499-511.

38. Mangeat B, Gers-Huber G, Lehmann M, Zufferey M, Luban J, Piguet V: HIV-1 Vpu neutralizes the antiviral factor Tetherin/BST-2 by binding it and directing its beta-TrCP2-dependent degradation. PLoS Pathog 2009, 5: e1000574.

39. Goffinet C, Allespach I, Homann S, Tervo HM, Habermann A, Rupp D, Oberbremer L, Kern C, Tibroni N, Welsch S, et al: HIV-1 antagonism of
CD317 is species specific and involves Vpu-mediated proteasomal degradation of the restriction factor. Cell Host Microbe 2009, 5:285-297.

40. Dube M, Roy BB, Guiot-Guillain P, Mercier J, Binette J, Leung G, Cohen EA: Suppression of Tetherin-restricting activity upon human immunodeficiency virus type 1 particle release correlates with localization of Vpu in the trans-Golgi network. J Virol 2009, 83:4574-4590.

41. Douglas JL, Viswanathan K, McCarroll MN, Gustin JK, Fruh K, Moses AV: Vpu directs the degradation of the human immunodeficiency virus restriction factor BST-2/Tetherin via a \{beta\}TrCP-dependent mechanism. J Virol 2009, 83:7931-7947.

42. Hauser H, Lopez LA, Yang SJ, Oldenburg JE, Exline CM, Guatelli JC, Cannon PM: HIV-1 Vpu and HIV-2 Env counteract BST-2/tetherin by sequestration in a perinuclear compartment. Retrovirology 2010, 7:51.

43. Zhang F, Wilson SJ, Landford WC, Virgen B, Gregory D, Johnson MC, Munch J, Kirchhoff F, Bieniasz PD, Hatziioannou T: Nef proteins from simian immunodeficiency viruses are tetherin antagonists. Cell Host Microbe 2009, 6:54-67.

44. Jia B, Serra-Moreno R, Neidermyer W, Rahmberg A, Mackey J, Fofana IB, Johnson WE, Westmoreland S, Evans DT: Species-specific activity of SIV Nef and HIV-1 Vpu in overcoming restriction by tetherin/BST2. PLOS Pathog 2009, 5:e1000429.

45. Sauter D, Schindler M, Specht A, Landford WN, Munch J, Kim KA, Votteler J, Schubert U, Bibollet-Ruche F, Keele BF, et al: Tetherin-driven adaptation of $\mathrm{Vpu}$ and Nef function and the evolution of pandemic and nonpandemic HIV-1 strains. Cell Host Microbe 2009, 6:409-421.

46. Gupta RK, Mlcochova P, Pelchen-Matthews A, Petit SJ, Mattiuzzo G, Pillay D, Takeuchi Y, Marsh M, Towers GJ: Simian immunodeficiency virus envelope glycoprotein counteracts tetherin/BST-2/CD317 by intracellular sequestration. Proc Natl Acad Sci USA 2009, 106:20889-20894.

47. Le Tortorec A, Neil SJ: Antagonism to and intracellular sequestration of human tetherin by the human immunodeficiency virus type 2 envelope glycoprotein. J Virol 2009, 83:11966-11978.

48. Jolly C, Booth NJ, Neil SJ: Cell-cell spread of human immunodeficiency virus type 1 overcomes tetherin/BST-2-mediated restriction in T cells. $J$ Virol 2010, 84:12185-12199.

49. Casartelli N, Sourisseau M, Feldmann J, Guivel-Benhassine F, Mallet A, Marcelin AG, Guatelli J, Schwartz O: Tetherin restricts productive HIV-1 cell-to-cell transmission. PLoS Pathog 2010, 6:e1000955.

50. Kuhl BD, Sloan RD, Donahue DA, Bar-Magen T, Liang C, Wainberg MA: Tetherin restricts direct cell-to-cell infection of HIV-1. Retrovirology 2010, 7:115.

51. Harman AN, Wilkinson J, Bye CR, Bosnjak L, Stern JL, Nicholle M, Lai J, Cunningham AL: HIV induces maturation of monocyte-derived dendritic cells and Langerhans cells. J Immunol 2006, 177:7103-7113.

52. Wu L, Martin TD, Vazeux R, Unutmaz D, KewalRamani VN: Functional evaluation of DC-SIGN monoclonal antibodies reveals DC-SIGN interactions with ICAM-3 do not promote human immunodeficiency virus type 1 transmission. J Virol 2002, 76:5905-5914.

53. Janas $A M$, Dong $C$, Wang $J H, W u L$ : Productive infection of human immunodeficiency virus type 1 in dendritic cells requires fusionmediated viral entry. Virology 2008, 375:442-451

54. Habermann A, Krijnse-Locker J, Oberwinkler H, Eckhardt M, Homann S, Andrew A, Strebel K, Krausslich HG: CD317/tetherin is enriched in the HIV1 envelope and downregulated from the plasma membrane upon virus infection. J Virol 2010, 84:4646-4658.

55. Hammonds J, Wang JJ, Yi H, Spearman P: Immunoelectron microscopic evidence for Tetherin/BST2 as the physical bridge between HIV-1 virions and the plasma membrane. PLoS Pathog 2010, 6:e1000749.

56. McDonald D, Vodicka MA, Lucero G, Svitkina TM, Borisy GG, Emerman M, Hope TJ: Visualization of the intracellular behavior of HIV in living cells. $J$ Cell Biol 2002, 159:441-452.

57. Wang JH, Wells $\mathrm{C}$, Wu L: Macropinocytosis and cytoskeleton contribute to dendritic cell-mediated HIV-1 transmission to CD4+ T cells. Virology 2008, 381:143-154

58. Garcia E, Pion M, Pelchen-Matthews A, Collinson L, Arrighi JF, Blot G, Leuba F, Escola JM, Demaurex N, Marsh M, Piguet V: HIV-1 trafficking to the dendritic cell-T-cell infectious synapse uses a pathway of tetraspanin sorting to the immunological synapse. Traffic 2005, 6:488-501.

59. Schindler M, Rajan D, Banning C, Wimmer P, Koppensteiner H, Iwanski A, Specht A, Sauter D, Dobner T, Kirchhoff F: Vpu serine 52 dependent counteraction of tetherin is required for HIV-1 replication in 
macrophages, but not in ex vivo human lymphoid tissue. Retrovirology 2010, 7:1.

60. Miyagi E, Andrew AJ, Kao S, Strebel K: Vpu enhances HIV-1 virus release in the absence of Bst-2 cell surface down-modulation and intracellular depletion. Proc Natl Acad Sci USA 2009, 106:2868-2873.

61. Neil SJ, Sandrin V, Sundquist WI, Bieniasz PD: An interferon-alpha-induced tethering mechanism inhibits HIV-1 and Ebola virus particle release but is counteracted by the HIV-1 Vpu protein. Cell Host Microbe 2007, 2:193-203.

62. Wang JH, Kwas C, Wu L: Intercellular Adhesion Molecule (ICAM)-1, But Not ICAM-2 and -3, Is Important for Dendritic Cell-mediated Human Immunodeficiency Virus Type-1 Transmission. J Virol 2009, 83:4195-4204

63. Jolly C, Booth NJ, Neil SJ: Cell-cell spread of human immunodeficiency virus type 1 overcomes tetherin/BST-2-mediated restriction in T cells. J Virol 2010, 84:12185-12199.

64. Pion M, Granelli-Piperno A, Mangeat B, Stalder R, Correa R, Steinman RM, Piguet $\mathrm{V}$ : APOBEC3G/3F mediates intrinsic resistance of monocytederived dendritic cells to HIV-1 infection. J Exp Med 2006, 203:2887-2893.

65. Olivetta E, Percario Z, Fiorucci G, Mattia G, Schiavoni I, Dennis C, Jager J, Harris M, Romeo G, Affabris E, Federico M: HIV-1 Nef induces the release of inflammatory factors from human monocyte/macrophages: involvement of Nef endocytotic signals and NF-kappa B activation. $J$ Immunol 2003, 170:1716-1727.

66. Messmer D, Jacque JM, Santisteban C, Bristow C, Han SY, VillamideHerrera L, Mehlhop E, Marx PA, Steinman RM, Gettie A, Pope M: Endogenously expressed nef uncouples cytokine and chemokine production from membrane phenotypic maturation in dendritic cells. $J$ Immunol 2002, 169:4172-4182.

67. Harman AN, Lai J, Turville S, Samarajiwa S, Gray L, Marsden V, Mercier S, Jones K, Nasr N, Cumming H, et al: HIV infection of dendritic cells subverts the interferon induction pathway via IRF1 and inhibits type 1 interferon production. Blood 2011.

68. Wang JH, Janas AM, Olson WJ, KewalRamani VN, Wu L: CD4 coexpression regulates DC-SIGN-mediated transmission of human immunodeficiency virus type 1. J Virol 2007, 81:2497-2507.

69. Janas AM, Wu L: HIV-1 interactions with cells: from viral binding to cellcell transmission. Curr Protoc Cell Biol 2009, Chapter 26(Unit 26):25.

70. Freed EO, Englund G, Martin MA: Role of the basic domain of human immunodeficiency virus type 1 matrix in macrophage infection. J Virol 1995, 69:3949-3954.

71. Schubert U, Clouse KA, Strebel K: Augmentation of virus secretion by the human immunodeficiency virus type $1 \mathrm{Vpu}$ protein is cell type independent and occurs in cultured human primary macrophages and lymphocytes. J Virol 1995, 69:7699-7711.

72. Petit C, Buseyne F, Boccaccio C, Abastado JP, Heard JM, Schwartz O: Nef is required for efficient HIV-1 replication in cocultures of dendritic cells and lymphocytes. Virology 2001, 286:225-236.

doi:10.1186/1742-4690-8-26

Cite this article as: Coleman et al:: Tetherin does not significantly restrict dendritic cell-mediated HIV-1 transmission and its expression is upregulated by newly synthesized HIV-1 Nef. Retrovirology 2011 8:26.

\section{Submit your next manuscript to BioMed Central and take full advantage of:}

- Convenient online submission

- Thorough peer review

- No space constraints or color figure charges

- Immediate publication on acceptance

- Inclusion in PubMed, CAS, Scopus and Google Scholar

- Research which is freely available for redistribution

Submit your manuscript at www.biomedcentral.com/submit
Biomed Central 